novozymes

\title{
DECREASE Final Technical Report \\ Development of a Commercial Ready Enzyme Application System for Ethanol
}

Dr. Sarah A Teter, Novozymes, Inc., Principle Investigator

April 2012

Prepared for the U.S. Department of Energy under Award Number: DE-FC36-08G018080

Project Team: Novozymes, Inc (Davis, CA, USA); Novozymes, A/S (Bagsvaerd, Denmark);

Novozymes Investment, China (Beijing, China); Pacific Northwest National Laboratory (Richland, WA, USA); Université de la Méditerranée and Universite de Provence (France); Cornell University (Ithaca, NY, USA). 


\section{Executive Summary}

Conversion of biomass to sugars plays a central in reducing our dependence on petroleum, as it allows production of a wide range of biobased fuels and chemicals, through fermentation of those sugars. The DECREASE project delivers an effective enzyme cocktail for this conversion, enabling reduced costs for producing advanced biofuels such as cellulosic ethanol. Benefits to the public contributed by growth of the advanced biofuels industry include job creation, economic growth, and energy security.

The DECREASE primary project objective was to develop a two-fold improved enzyme cocktail, relative to an advanced cocktail (CZP00005) that had been developed previously (from 2000-2007). While the final milestone was delivery of all enzyme components as an experimental mixture, a secondary objective was to deploy an improved cocktail within 3 years following the close of the project.

In February 2012, Novozymes launched Cellic ${ }^{\circledR}$ CTec3, a multi-enzyme cocktail derived in part from components developed under DECREASE. The externally validated performance of CTec3 and an additional component under project benchmarking conditions indicated a 1.8-fold dose reduction in enzyme dose required for $90 \%$ conversion (based on all available glucose and xylose sources) of NREL dilute acid pretreated $\mathrm{PCS}$, relative to the starting advanced enzyme cocktail.

While the ability to achieve $90 \%$ conversion is impressive, targeting such high levels of biomass digestion is likely not the most cost effective strategy. Novozymes' techno economic modeling showed that for NREL's dilute acid pretreated corn stover (PCS), 80\% target conversion enables a lower total production cost for cellulosic ethanol than for $90 \%$ conversion, and this was also found to be the case when cost assumptions were based on the NREL 2002 Design Report [1]. A 1.8X dose-reduction was observed for $80 \%$ conversion in the small scale (50 g) DECREASE benchmark assay for CTec3 and an additional component. An upscaled experiment (in $0.5 \mathrm{~kg}$ kettle reactors) was performed to compare the starting enzyme mixture CZP00005 with CTec3 alone; these results indicated a $1.9 \mathrm{X}$ dose- reduction for $80 \%$ conversion.

The CTec3 composition does not include the best available enzyme components from the DECREASE effort. While these components are not yet available in a commercial product, experimental mixtures were assayed in a smaller scale assay using DECREASE PCS, at high solids loadings (21.5\% TS). The results indicated that the newer mixtures required $2.9 X$-less enzyme for $90 \%$ conversion, and $3.2 X$-less enzyme for $80 \%$ conversion, relative to the starting enzyme cocktail. In conclusion, CTec3 delivers a 1.8-1.9X dose reduction on NREL PCS at high solids loadings, and the next generation enzyme from Novozymes will continue to show dramatically improved biochemical performance. CTec3 allows reduced costs today, and the experimental cocktails point to continued biotechnological improvements that will further drive down costs for biorefineries of tomorrow. 


\section{Acronyms and Abbreviations}

bG beta-glucosidase; a component of Novozymes' enzyme cocktails which converts soluble glucooligomers to glucose, and is critical for alleviating end product inhibition of other components in the mixture

CBH I Cellobiohydrolase I; an exoglucanase that processively cleaves cellulose, moving from the reducing end of cellulose chains

CBH II Cellobiohydrolase II; an exoglucanase that processively cleaves cellulose, moving from the non-reducing end of cellulose chains

CZP00005 DECREASE starting enzyme cocktail, a specific lot of an advanced enzyme cocktail that was produced at commercial scale. The enzyme components in this cocktail were developed at Novozymes (2000-2007).

EG endoglucanase; cleaves cellulose chains internally, creating new reducing and non-reducing ends for $\mathrm{CBHs}$ to act upon

GH61 Glycoside hydrolase family 61, a unique family of copper-dependent oxidases that require redox active cofactors to cleave cellulose to cellodextrin and oxidized cellodextrin products

HTM High Temperature Mix. A mixture of monocomponent enzymes showing a relative improvement in performance over a previous best mixture which is achieved by thermostabilization and improved thermal activity.

PCS pretreated corn stover, specifically dilute-acid pretreated material provided by the National Renewable Energy Laboratory (NREL)

PNNL Pacific Northwest National Laboratory; refers to the fungal biotechnology group who were subcontractors on this award 


\section{Table of Contents}

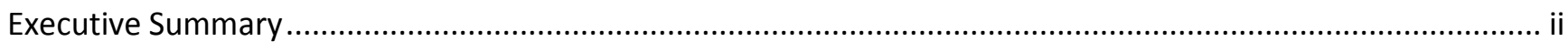

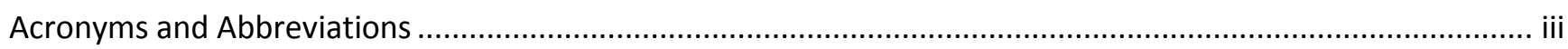

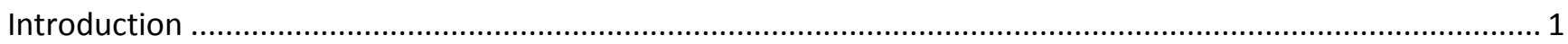

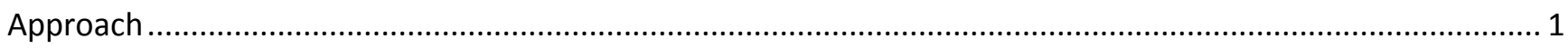

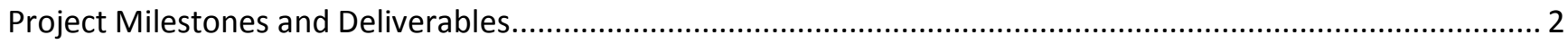

Task A Results: Actual accomplishments compared with original goals and objectives .................................. 2

Subtask A.1: Screening GH61 family for best combination of enhancers on PCS whole slurry........................... 2

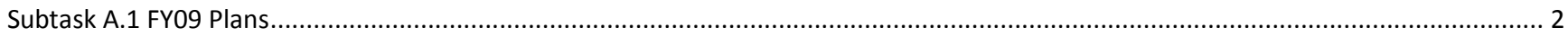

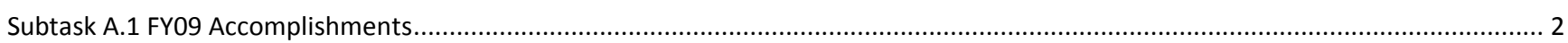

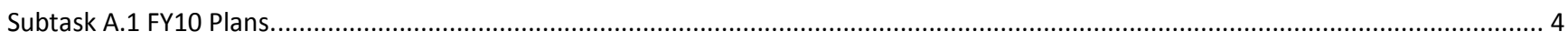

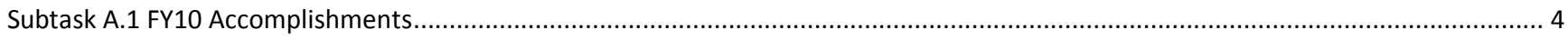

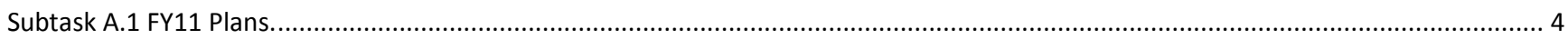

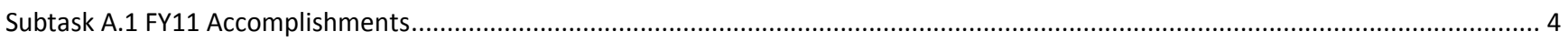

Subtask A.2: Improve stability of most labile component(s) in the current enzyme system .............................. 4

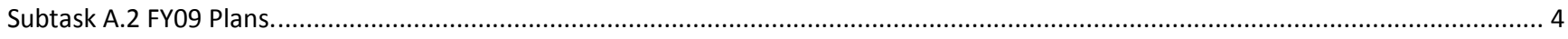

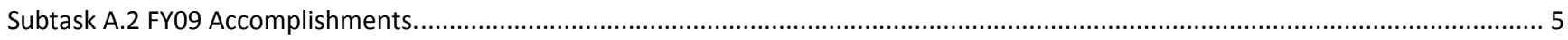

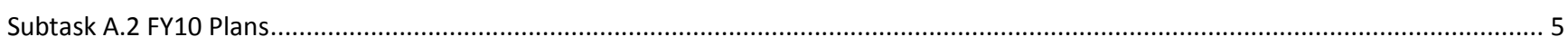

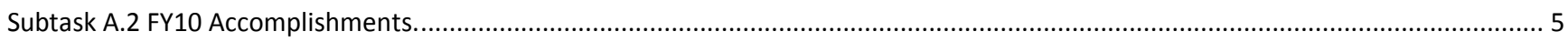

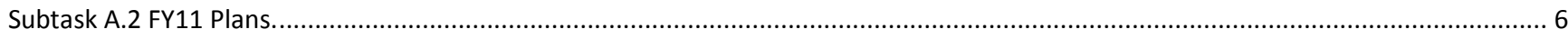

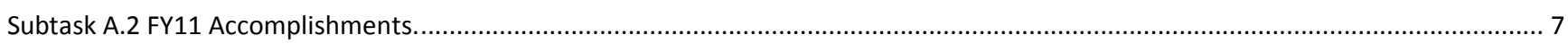

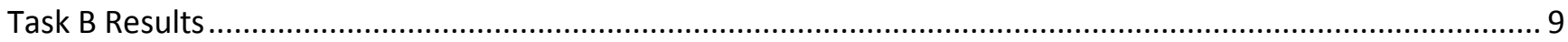

Subtask B.1-B.3 Primary screening, "synergy" assay, and identification and isolation of proteins responsible for

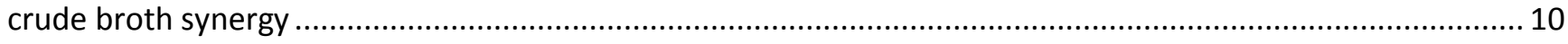

Subtask B. 1-3 FY09 Plans........................................................................................................................................... 10

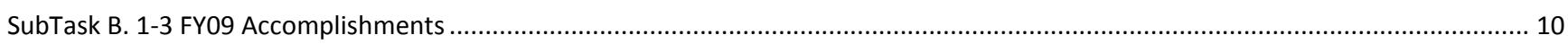

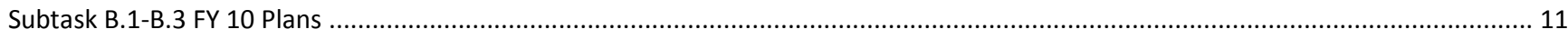

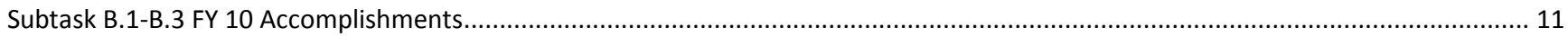

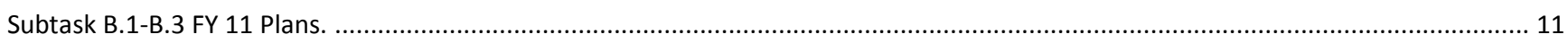

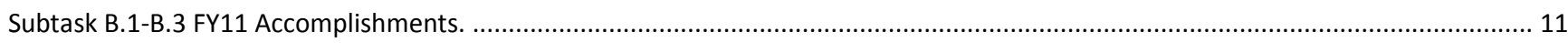

Subtask B.4. Cloning, expression and characterization of novel biomass active enzymes which are not

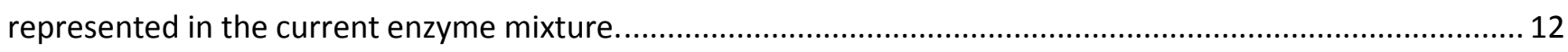

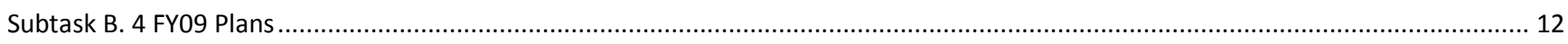

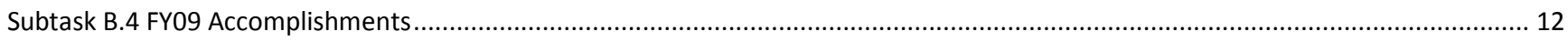

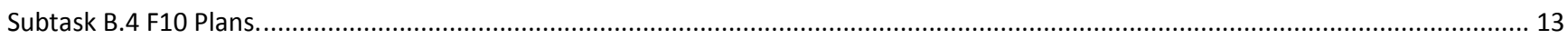

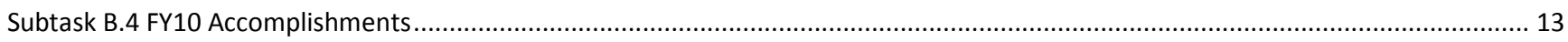

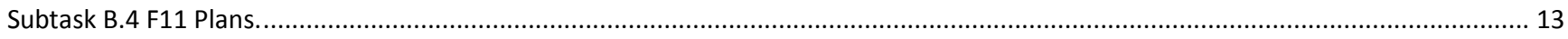


DECREASE Final Technical Report, Novozymes Inc. DE-FC36-08G018080

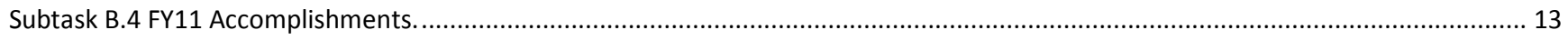

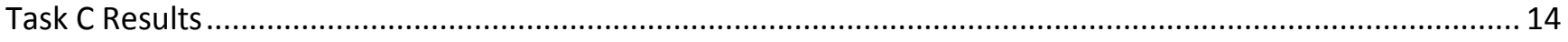

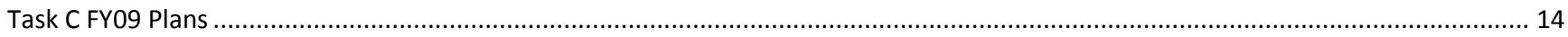

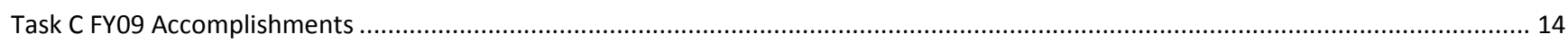

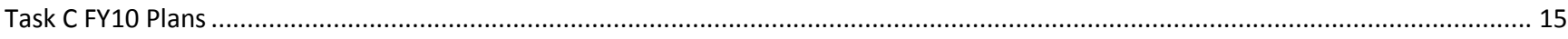

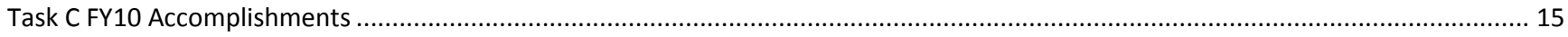

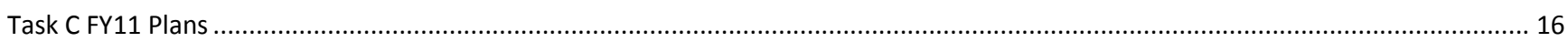

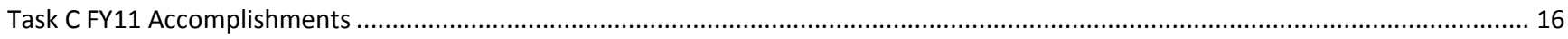

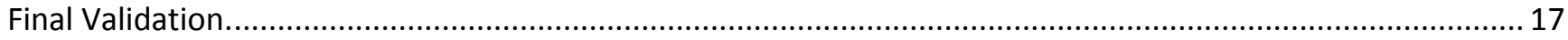

Validation of CTec3 performance on DECREASE in a kettle reactor, at 50 으............................................. 20

Assessing overall project fold improvements, including HTM candidates not present in final validation ........... 21

Conclusion: actual accomplishments compared with original goals and objectives ........................................ 23

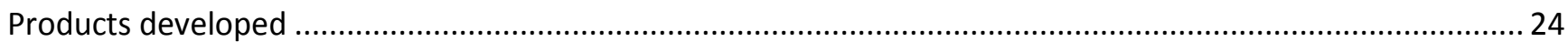

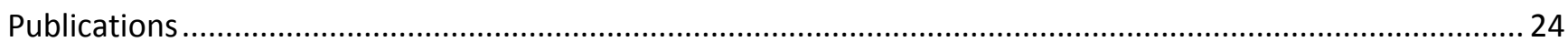

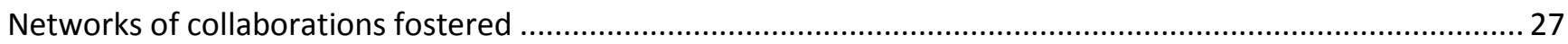

Web site or other internet sites that reflect the results of the project........................................................... 27

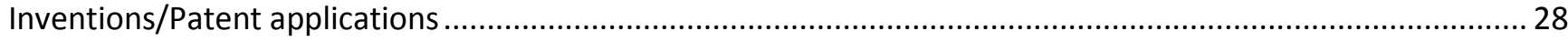




\section{Introduction}

Starting with an advanced biomass enzyme preparation, Novozymes' objective was to develop a two-fold improvement in specific performance, defined by halving the needed enzyme dose that allows for $90 \%$ conversion (assayed under predefined conditions). The intent was to provide an enzyme system which Novozymes would deploy commercially, within three years following the close of the project, that would enable biomass ethanol producers launch their ethanol production technology at commercial scale.

For the purposes of benchmarking progress on this award, dilute-acid pretreated corn stover (PCS), provided by the National Renewable Energy Laboratory (NREL), was used to assess improvements in enzyme performance. Based on past biochemical improvements, we expected that improvements measured using this feedstock would correlate to similar or more significant performance improvements on other pretreated biomass residues. This expectation was verified through assays performed with various other pretreated feedstocks that were pretreated internally or provided by our customers and collaborators.

\section{Approach}

DECREASE work focused entirely on discovery and engineering of improved enzyme systems for biomass conversion to sugars. Two philosophies underlie our approach to enzyme improvement: 1) better candidates for known enzyme components exist in nature, or can be engineered in the lab and 2) our understanding of the enzyme paraphernalia that exists in nature to allow for effective biomass deconstruction is incomplete; important classes of proteins may still be discovered.

An overview of the original tasks which reflect these two approaches is provided:

Task A: Improvement of enzyme system components in Novozymes' starting enzyme system

We planned two strategies for improving components that make up the starting enzyme cocktail, based on likelihood that replacement of an existing component would improve performance of the overall enzyme system.

Task B: Identification of synergistic proteins to improve the starting enzyme system performance

This strategy rested on our previous natural diversity screening programs, which had yielded novel proteins capable of enhancing the activity of our cellulolytic cocktail. New enzymes or proteins culled from natural diversity would also replace specific components of the starting best cellulase system that are "weak links" with respect to specific activity, stability, or other performance relevant factors.

Task C: Project Management and Reporting

Under this task, the technical progress on the first two tasks would be assessed and benchmarked, allowing for reports and other deliverables to be provided as stipulated in the award. We planned to further validate performance through technical audits conducted by NREL, under guidance of the DOE. 


\title{
Project Milestones
}

The Project Milestones were as follows:

Deliver an enzyme mixture capable of 1.5 -fold improved performance compared to the starting biomass enzyme system (by 18-22 months after the start of the project)

Final milestone: deliver an enzyme mixture capable of two-fold improved performance compared to the starting biomass enzyme system

\section{Task A Results: Actual accomplishments compared with original goals and objectives}

\author{
Subtask A.1: Screening GH61 family for best combination of enhancers on PCS \\ whole slurry. Prior to DECREASE, we had discovered that specific glycoside hydrolase family 61 (GH61) \\ proteins enhance the overall performance of enzymes in saccharification of complex lignocellulose [2]. \\ Inclusion of GH61, inclusion as a small percentage in a cellulolytic cocktail, resulted in improved performance \\ of the total enzyme system. During a previous DOE-funded enzyme improvement project, less than $20 \mathrm{GH} 61$ \\ genes were cloned, expressed and assayed, and effective enhancers for the hydrolysis of washed PCS were \\ identified. Given the success in identifying an effective GH61 from such a small pool of candidates, we \\ reasoned that an improved molecule might be identified from a larger screening campaign.
}

Subtask A.1 FY09 Plans For the first year of work, we planned to clone and express a target number of GH61s, screen their ability to enhance whole slurry PCS hydrolysis, and identify the optimal combination of GH61s in a mixture. We also planned work on understanding the basis for GH61s improved enhancer activity in the presence of pretreatment liquor (vs. washed PCS). The goal for this subtask was to obtain an improved GH61 in the first year of work.

Subtask A.1 FY09 Accomplishments. We easily exceeded our target number of novel GH61s cloned, expressed, and characterized, and discovered a number of novel GH61 enhancers. We identified one GH61 with equivalent performance to the GH61 in our benchmark (in our starting advanced enzyme mixture). The new candidate was superior in expression potential relative to the GH61 in the starting enzyme mixture, allowing us to express it at higher levels in $T$. reesei, thus allowing us to leverage a greater benefit by including a higher dose of the protein in a complete mixture (Figure 1). 

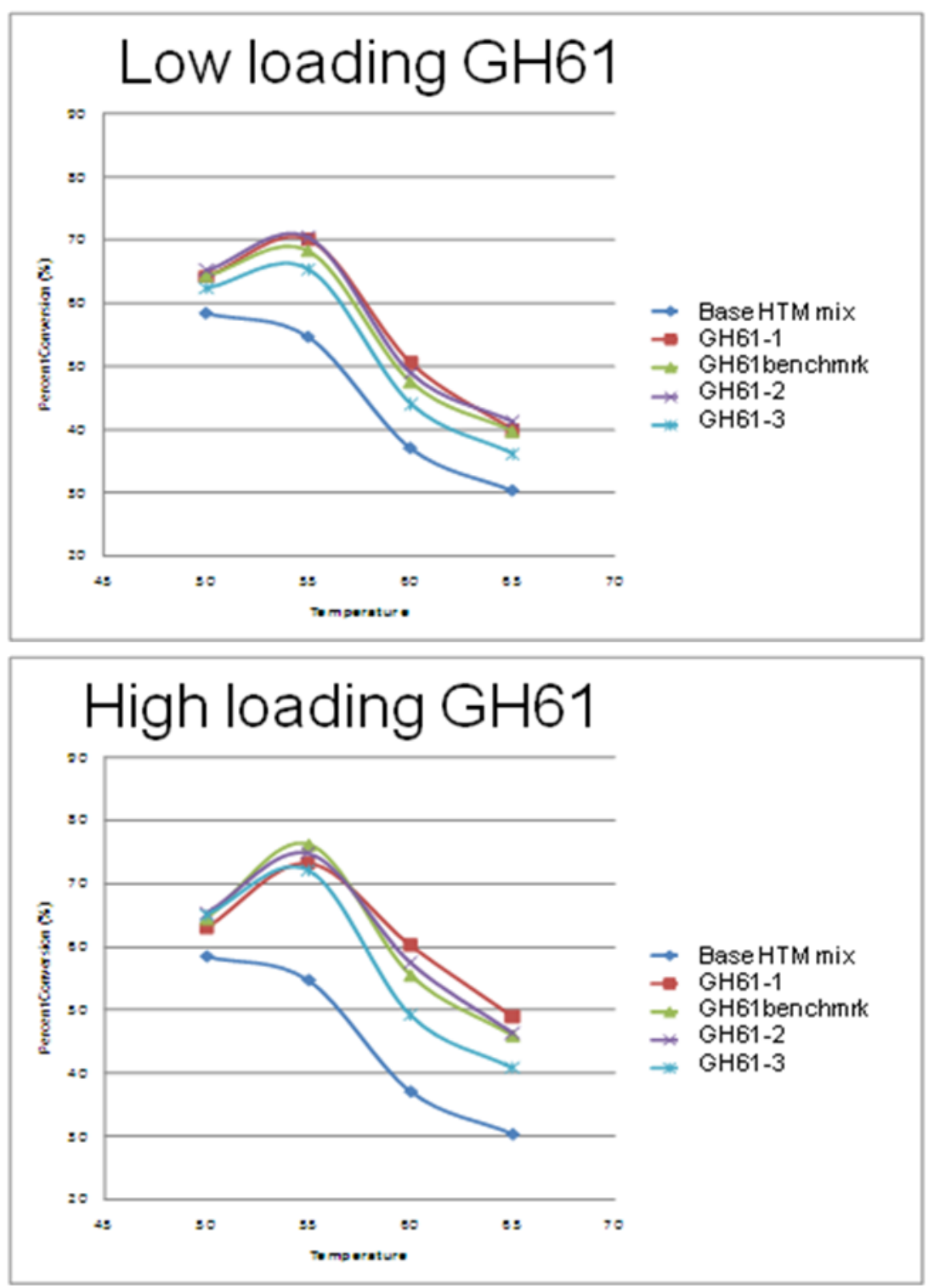

Figure 1. Relative fold-enhancment by inclusion of GH61 is improved at higher loading of GH61 (as a ratio of total protein). The relative impact of GH61 inclusion in the mixture is more dramatic at high loading (bottom panel) than it is at lower loading (top panel). NREL PCS was hydrolyzed by an enzyme cocktail containing $T$. reesei broth and candidate thermostable enzymes of a High Temperature Mix (HTM). The assay was performed in screening mode (5\% TS, using washed substrate, 3 day hydrolysis). Dark blue shows performance of the base cocktail with no added GH61. The green line shows the improved performance resulting from addition of the GH61 found in the benchmark enzyme cocktail ("GH61benchmark"). Other GH61s show equivalent peformance (red, purple, light blue). Percent conversion of cellulose to glucose is shown.

We made progress in clarifying the mode of action of GH61, discovering that a soluble component(s) potentiate optimal performance. We then made a technical breakthrough in the discovery that a combination of GH61A and gallic acid can fragment cellulose into smaller oligosaccharides, as detected by mass spectrometry and carbohydrate gel electrophoresis. Naturally occuring cofactors were shown to be present in pretreated biomass liquor. 
Subtask A.1 FY10 Plans. We planned to lessen the focus on discovery of novel GH61s, and to expend more effort on mixture design. We planned continued work on understanding the mechanism whereby GH61 improves activity, toward further optimizing the performance of this critical component.

Subtask A.1 FY10 Accomplishments. We identified additional GH61s which performed well in reducing enzyme dose for cellulose hydrolysis in base enzyme cocktails. We published our earlier work demonstrating the beneficial impact of GH61 on cellulolytic enzyme performance [3]. The crystal structure of a highly active GH61 protein was also published in this paper (obtained through a collaboration outside DECREASE).

Toward understanding the molecular mechanism of GH61, activity was shown to be enhanced by a number of small redox-active cofactors such as ascorbate and gallate. We showed that metal cations such as copper are required in addition to the redox cofactors for GH61-mediated cleavage resulting in formation of cellodextrin and oxidized cellodextrin products.

Subtask A.1 FY11 Plans. While maintaining a baseline effort in cloning and expressing candidate enzymes for screening, we planned to finalize selection of GH61(s) and determining optimal content of the component in our improved enzyme cocktails.

Subtask A.1 FY11 Accomplishments. By the conclusion of the third year of our project, we had selected a candidate GH61 for benchmarking. That enzyme had been expressed at appropriate levels in our expression host (strain construction accomplished outside DECREASE). We published our findings on GH61 mechanistic details, along with findings relating to the structure of the metalloenzyme active site, which were obtained through collaborations outside DECREASE $[4,5]$.

\section{Subtask A.2: Improve stability of most labile component(s) in the current enzyme system}

Prior to DECREASE, we had identified inactivation of CBH II as a "weak link" in our starting enzyme cocktail. We therefore initially planned to clone new $\mathrm{CBH}$ Ils, engage in rational design of our best current $\mathrm{CBH}$ II to improve its thermostability, specific activity, and/or other instability, and perform random mutagenesis and directed evolution of our current best $\mathrm{CBH}$ II.

After initial success, we found that improving a single "weak link" in the enzyme mixture led to identification of new suboptimal components. These represented routes to improving the performance of the complex mixture, through stabilization and individual biochemical improvement. Our strategy soon morphed into one of iterative improvement of numerous "weak link" components. We focused on the high temperature stability and activity of monocomponent mixtures containing all crititcal enzyme components for effective PCS hydrolysis. We called the mixture a "High Temperature Mix"- HTM for short. Success on this subtask led us to increase the resources associated with this effort.

Subtask A.2 FY09 Plans. The initial target was to assess candidate GH6 components as replacements for Trichoderma reesei $\mathrm{CBH}$ II, and generate a targeted number of new lead molecules from screening naturally occurring GH6s as well as engineered and evolved variants. Specific targets for directed evolution of GH6s were planned. 
Subtask A.2 FY09 Accomplishments. Obtaining improved GH6s through screening of natural diversity and protein engineering was successful. We exceeded our target for a number of wild type CBHIls to be cloned and expressed, and also made progress through protein engineering. Specifically, when temperature profiles of CBHII activity on PCS were compared, using a thermostable bG and the CBH II candidates, the CBH II in our starting enzyme cocktail was inferior at its optimal temperature $(50 \stackrel{\circ}{\circ}$ ) relative to a wild type $\mathrm{CBH}$ II candidate at its optimal temperature $(60 \stackrel{\circ}{\circ})$, and to a further improved variant of that wild type GH6 at its optimal temperature $(65 \stackrel{\circ}{\circ})$.

Starting in this first year of work we recognized a need for replacing other components in the enzyme cocktail with improved enzymes of the same class. We initiated work on obtaining improved HTMs. During the first year, hypotheses about which components might be limiting in the enzyme cocktail were drawn based on mechanistic analyses. In addition, we knew from our natural diversity screening work under Task B that addition of endoxylanases could improve enzyme performance (see Task B Results). We included xylanases in our HTM, and focused on surveying xylanase diversity to obtain best enzyme in this class.

We cloned, expressed and tested over 30 bG candidates, and identified candidates with improved performance relative to the bG in our starting enzyme mixture. For xylanases, we surveyed over 100 candidates among various GH families, and probed xylanase synergies with other components in the mix. By the close of year one, we had a strong understanding of dose requirements for xylanase, and a handful of candidate xylanses for further benchmarking in the context of an improved HTM. In addition, we cloned, expressed and analyzed a number of $\mathrm{CBH}$ Is, and EGs, though the throughput was lower than for the aforementioned classes.

Subtask A.2 FY10 Plans. Having in hand a highly active CBH II, we aimed to replace additional "weak link" components. At this stage, the HTM at 55 ㄷ C enabled dose reductions compared to our starting enzyme system at $50 \stackrel{\circ}{ }$, which inspired us to push towards even further stabilization and high temperature activity.

At the close of the first year, analyses indicated that endoglucanase (EG) activity might be deficient in our current best HTM. This lead us to target cloning, express, and characterization of EGs with high specific performance on PCS at temperatures of $55 \stackrel{\circ}{\circ}$ and higher.

Also during FY2010, we aimed to further improve the performance of beta-glucosidase (bG). Analyses indicated that the bG in the HTM might not be optimal for performance, particularly at high solids loadings and at elevated temperature. Specific enzyme properties which needed to be improved were identified.

Subtask A.2 FY10 Accomplishments. As targeted, we obtained bG candidates with improved performance over the current beta-glucosidase (bG) in our benchmark mixture. We had discovered a particular wild type bG with excellent biochemical properties; specifically, the ability to catalyze conversion of glucooligomers to glucose in the presence of high levels of PCS liquor, and also in the presence of high concentrations of the end product ( $40 \mathrm{~g} / \mathrm{L}$ glucose). Unfortunately, we encountered difficulties in expressing this candidate at high enough levels in our intended production host.

We were able to overcome this problem through rational design. Starting with a bG which we had shown to be highly-expressed in T. reesei, we engineered mutations in the substrate binding pocket which dramatically 
improved the performance of the enzyme in application relevant conditions, when high concentrations of PCS liquor and high levels of glucose were present.

In addition to achieving the goals of improving these enzymes, we uncovered a $\mathrm{CBH}$ I which showed improved performance at high temperature relative to the $\mathrm{CBH}$ I in our original enzyme cocktail. Another successful replacement strategy was to focus on natural diversity among several families of xylanases. Following an early lead from Task B (as reported under Task B results), we showed that a large subset of xylanase candidates shows synergy with the starting biomass enzyme system, giving us excellent candidates for hydrolysis at $50 \stackrel{\circ}{ }$,

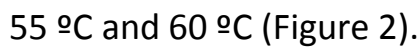

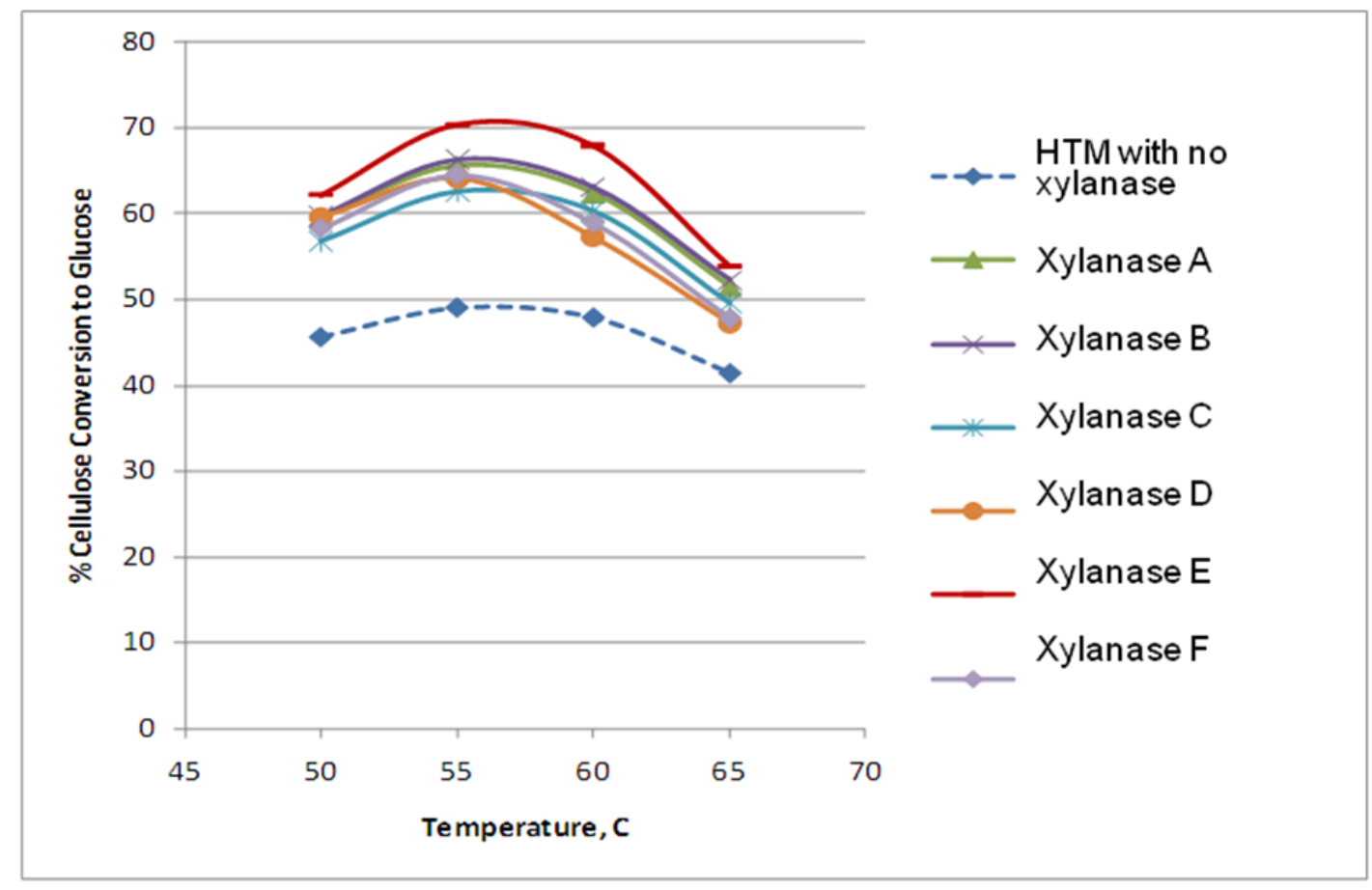

Figure 2. Temperature profiles of FY $\mathbf{1 0}$ xylanase candidates, activity on PCS. Wild type xylanase candidates were assayed in combination with a complete HTM. Cellulose conversion to glucose is shown (5\% TS), $72 \mathrm{hr}$ hydrolysis.

Subtask A.2 FY11 Plans. We aimed to continue HTM optimization by evaluating newly discovered and engineered candidates within each enzyme class by evaluating cocktail performance in a HTM. For CBH II, we expected that this might leverage use of our most optimal variant from protein engineering work, using the best wild type GH6 enzyme backbone from our diversity screening. The candidates from this effort would be combined with any candidates discovered under Task B. Under this task as well as Task B, mixture design experimentation was planned to determine the most efficient blend of enzyme components for hydrolysis of PCS under our benchmark conditions.

In order to support the goals for this final year of work, it was necessary to develop a miniaturized assay which could accommodate high substrate loadings. We planned to develop and roll out a "high solids mini assay" which would allow us to perform mixture design experiments at high solids, and also to compare performance of enzyme cocktails while not depleting enzyme stocks. 


\section{Subtask A.2 FY11 Accomplishments.}

We obtained superior candidates in most of the enzyme classes of interest during the final year of work. These components were not benchmarked in the $50 \mathrm{~g}$ validation benchmark. For this reason, we expect that our actual fold improvement in enzyme cocktails is greater than that reported in our validation benchmark, as discussed further under Task $\mathrm{C}$.

FY11 CBH I comparison Starting with CBH I replacement, in Q2 FY2011 we identified a wild type candidate, CBH $\mathrm{I}-\mathrm{B}$, which was obtained through targeted cloning and expression work, as shown in Figure 3A. The temperature profile shows that it had superior hydrolysis in the range of $55-65 \stackrel{\circ}{ }$, relative to the previous 2010 candidate ( $\mathrm{CBH}$ I-A), when combined with other components in a complete high temperature mix (we used the best known components at the time to create this HTM). Later in FY2011, we improved this CBH I-B further by protein engineering. The engineered $\mathrm{CBHI}-\mathrm{C}$ is shown in Figure 3B. In the context of the optimal HTM known in FY2011, the CBH I-C outperforms the previous best wild type CBH I-B at all temperatures tested $(50-65 \stackrel{\circ}{\circ})$.

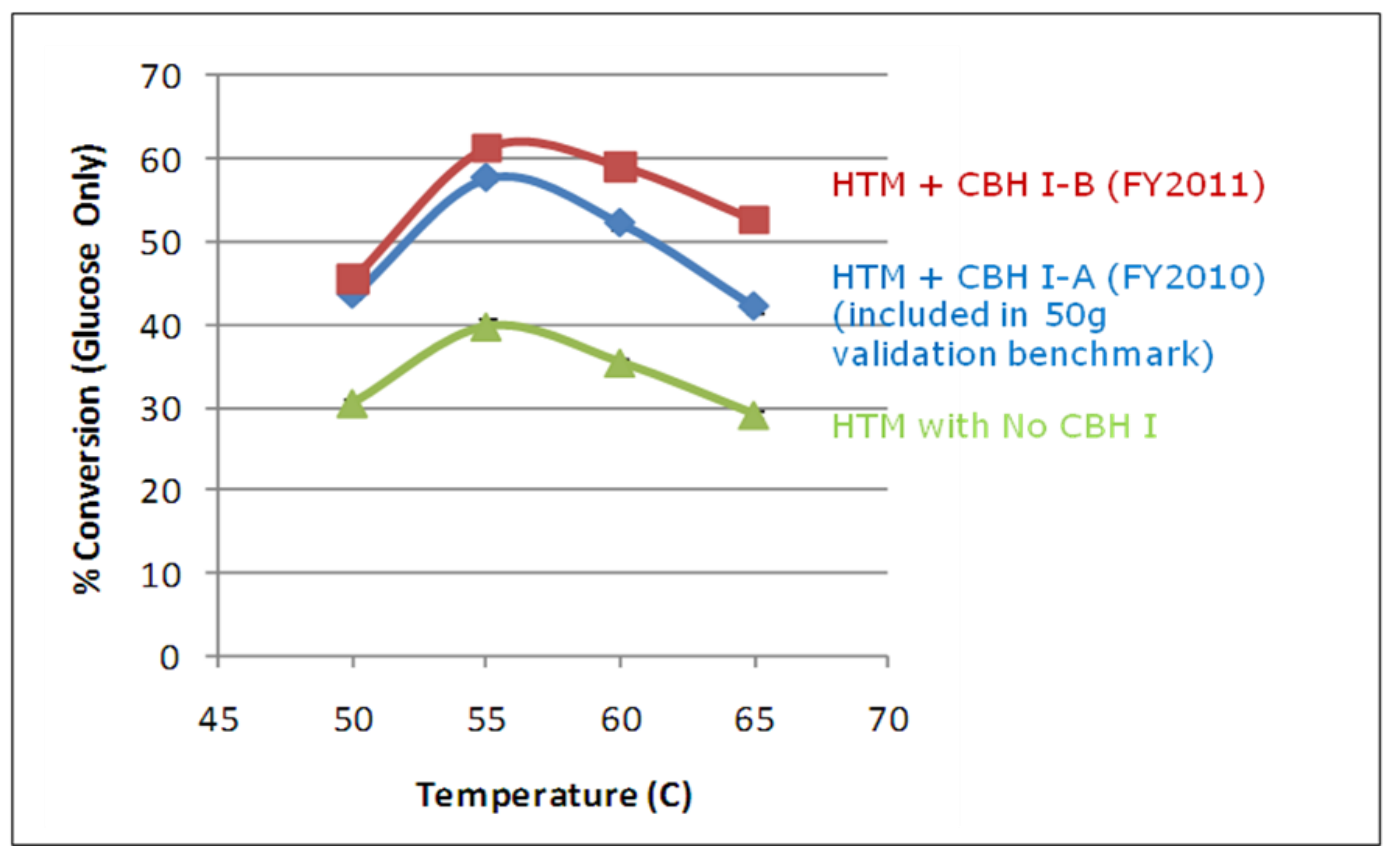




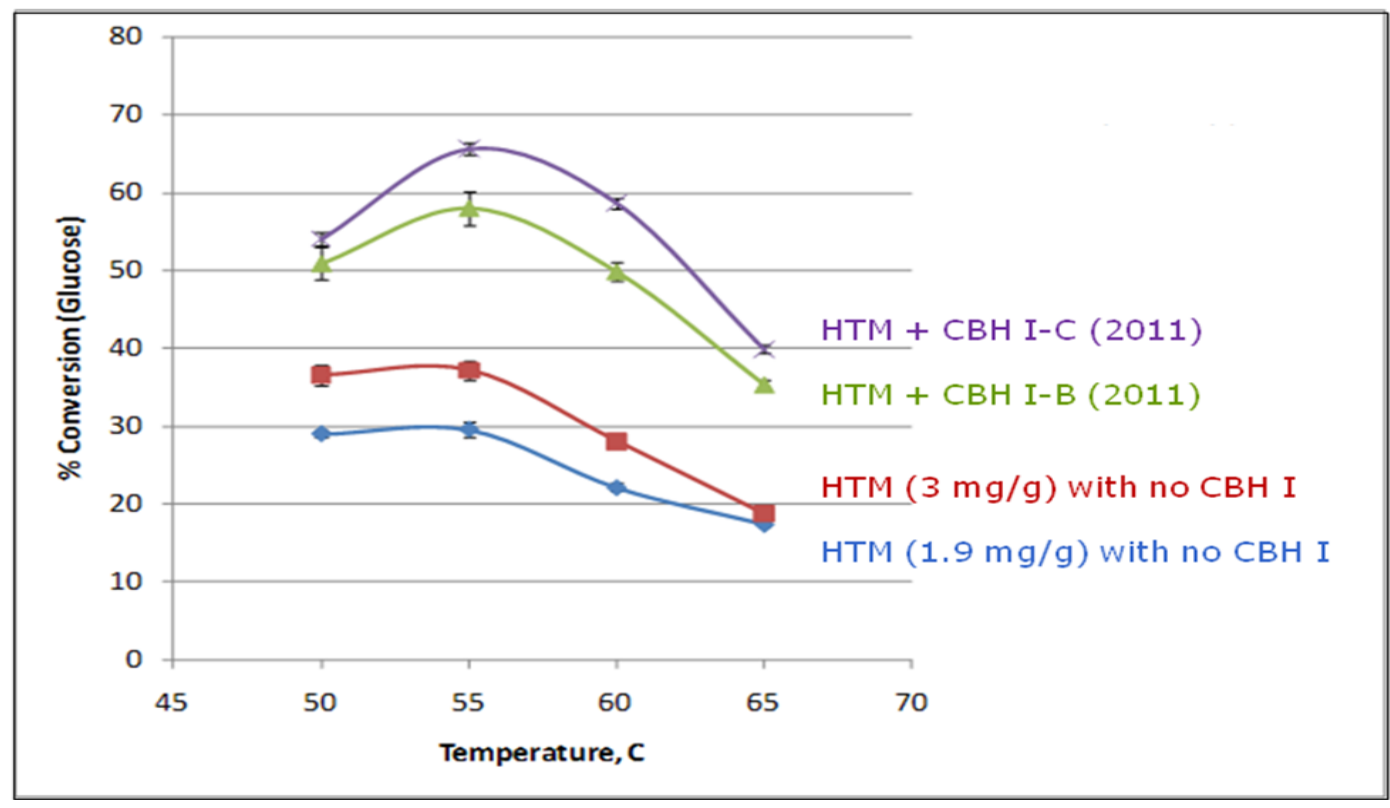

Figure 3. Comparison of CBH I candidates in different HTMs. Two different HTMs (containing top performing candidates in Q1 2011, and Q3 2011 in Panels A and B respectively), were analyzed, including different CBH I candidates. Substrate was $5 \%$ PCS, and the temperature profile of conversion of glucan to glucose is shown. $\mathbf{A}$. Green: no CBH I, blue: HTM with top CBH I from FY2010 (CBH I-A); red: HTM with CBH I-B. B. Purple: CBH I-C, engineered in Q3 FY2010, is compared to the previous best CBH-I B. Red and blue traces show cocktail performance without $\mathrm{CBH}$ I at two different loadings.

FY11 CBH II Comparison. During the final year of work, we obtained better CBH Ils, including one wild type gene obtained from enzyme diversity screening, and another developed through protein engineering. The protein engineering entailed improving the thermal stability of a well-expressed wild type candidate. Figure 4 compares the performance of these top two CBH IIs in the context of a complete HTM. In green, the engineered variant $\mathrm{CBH}$ II ( $\mathrm{CBH}$ II-C) was improved over the corresponding wild type parent gene (dark blue, $\mathrm{CBH}$ II-A). Another wild type CBH II (CBH II-B) is compared, in orange, and also shows high performance in the temperature range form 50-65 으. 


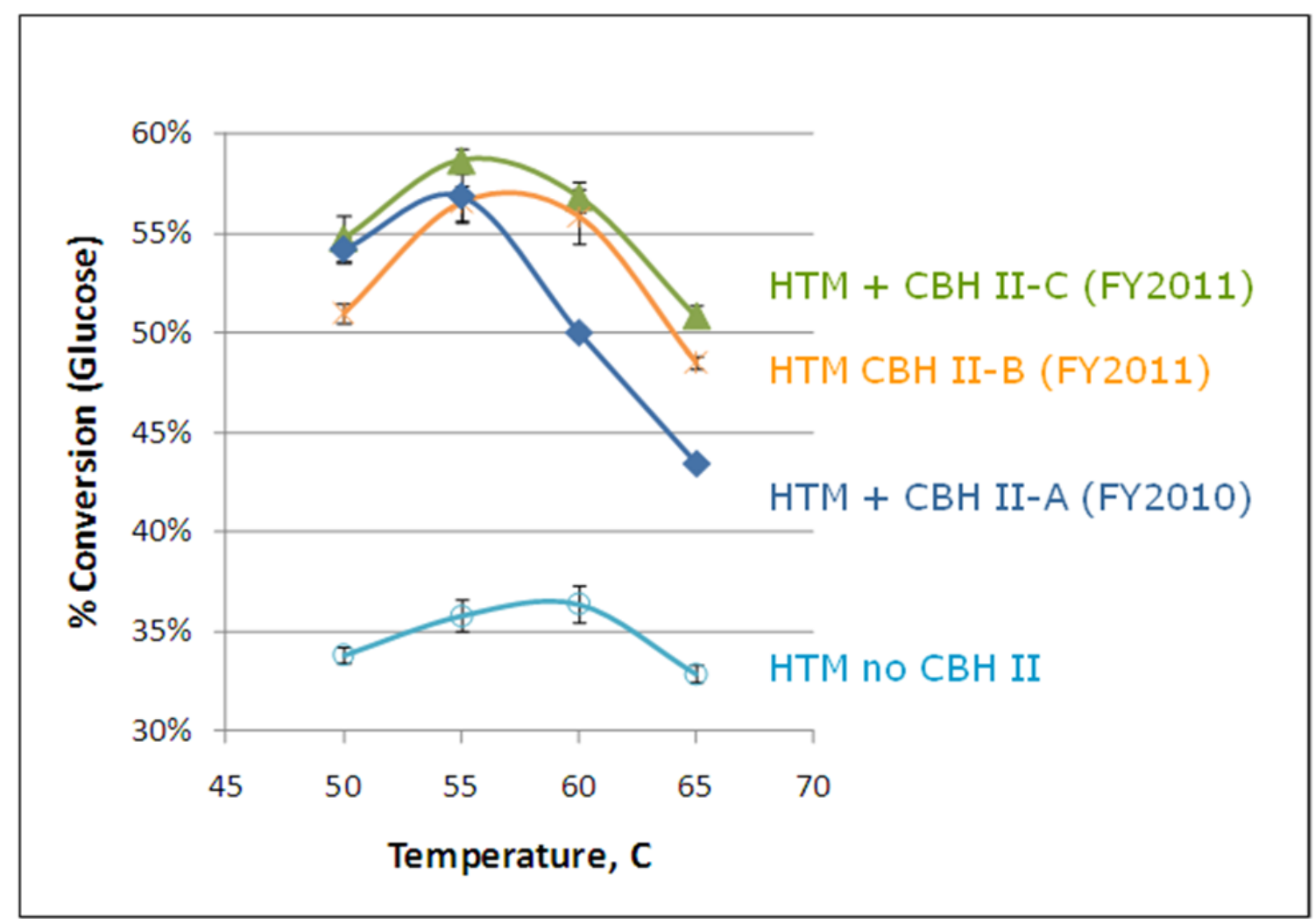

Figure 4. Comparison of CBH II candidates in an FY11 HTM. Complete HTM, including different CBH II candidates, was assayed on 5\% PCS, and the temperature profile of conversion of glucan to glucose is shown. Light blue: no CBH II, dark blue: HTM with top CBH II from FY2010 (CBH II-A). Green: HTM the engineered variant $\mathrm{CBH}$ II-C. The variant is improved over the wild type parent (dark blue). Orange: $\mathrm{CBH}$ II-B, another wild type $\mathrm{CBH}$ II was discovered that shows similar activity in mixtures compared to the engineered variant.

FY11 Other components. We identified potentially improved candidates in other enzyme classes during the final year of work. Upon verification, and demonstration of expression potential, these components may be utilized in a future enzyme product.

The work summarized in this section is based on comparisons made using a low solids screening, with the exception of our bG comparison, where we used a low solids assay combined with high glucose and PCS liquor (and also followed up in a larger format high solids assay). During the last year of work we developed a miniaturized high solids mini assay. The development of these assays allowed us to evaluate performance of monocomponent HTMs under high solids assay conditions, discussed under Task C.

\section{Task B Results}

The goal of Task B was to screen natural diversity to yield proteins which could enhance the activity of the starting biomass enzyme system. Given the fact that lignocellulose is degraded in nature by a complex consortia of microorganisms that work together to decompose plant matter, we hypothesized that a screen of natural diversity could yield additional proteins beyond those existing in the $T$. reesei-based biomass enzyme systems. An example of the potential that this approach was our discovery of GH61 as a stimulatory factor in 
DECREASE Final Technical Report, Novozymes Inc. DE-FC36-08G018080

lignocellulose hydrolysis. That discovery was made through a relatively small-scale screening of thermophilic fungi . The subtasks under this task were organized to allow for identification of novel types of components that were missing or deficient in the starting enzyme mix.

\section{Subtask B.1-B.3 Primary screening, "synergy" assay, and identification and isolation of proteins responsible for crude broth synergy}

Subtask B.1 covers growing microorganisms on cellulosic substrates, harvesting broth and quantifying total protein, and evaluating the specific performance (per mg total protein) of the crude broths for hydrolysis on PCS at a range of temperatures, and a variety of conditions. Comparisons were made to performance by $T$. reesei-based mixtures on a per $\mathrm{mg}$ protein basis.

Under subtask B.2, secondary screening of selected crude broths, we looked for synergy with T. reesei-based cocktails. The mixtures were tested in various ratios, and those fermentation broths demonstrating any detectable enhancement of our benchmark T. reesei cellulase system analyzed further in Subtask B.3.

Through a combination of protein fractionation and functional synergy assay, followed by proteomics analysis, we "deconvoluted" the complex broth mixtures under Subtask B.3, allowing us to uncover specific proteins that are capable of enhancing the performance of our benchmark mixtures. The approach required successful "upscaling" of fermentations of the promising wild type strains, which was accomplished at Novozymes and at PNNL. Cloning and expression of components identified by fractionation and proteomics was used to unambiguously determine whether a protein is capable of synergizing with our base enzyme cocktail.

As Subtasks B.1, B.2, and B.3 are highly interrelated, plans and accomplishments for these subtasks will be discussed together.

Subtask B. 1-3 FY09 Plans The initial work load on this task was quite high, with a target of screening over 1000 fungi and bacteria in the primary screen for synergy between crude broths from cultivated microorganisms and our enzyme cocktail. In secondary screening, we targeted upscaling the top 50 strains (10 to be fermented by PNNL). For those with verified synergy in the secondary assay, we planned fractionation of broths to allow identification of synergistic proteins. Based on past experience, we expected that we might discover two novel synergistic proteins within FY09.

SubTask B. 1-3 FY09 Accomplishments At the start of DECREASE, we already had a very active screening pipeline for assessing the biomass degrading activity of proteins secreted by diverse microorganisms. We easily achieved the stated goals with regard to the total throughput of the assay, by screening 1100 samples screened in primary assays, and $\sim 60$ screened for synergistic potential with benchmark enzyme cocktails). The start of work with our collaborators at PNNL was delayed, but by Q3, the first strain was transferred for scale up, and another was delivered in Q4. In addition to fractionation/proteomic discovery work to identify important enzymes in these broths, we accommodated leads from pre-DECREASE work to deconvolute complex broth mixtures that had been prioritized before the project started.

Fractionation of an synergistic broth led to the discovery that small doses of xylanase have a stimulatory effect on glucan conversion. As was discussed under Task A, this led us to rapidly explore xylanase diversity by 
DECREASE Final Technical Report, Novozymes Inc. DE-FC36-08G018080

characterizing known xylanases from a variety of classes. From this same broth, we discovered a CBH II candidate that had equivalent or slightly better performance than the starting candidates.

In addition to analyzing broths for synergy with our platform cellulase, we also measured performance of the crude broths alone. In this way, we were able to prioritize a number of organisms for gene discovery, based on performance at high temperature in hydrolysis of PCS. During the first year, the focus of the crude broth screening shifted from a discovery platform for novel components to a way for us to prioritize which organisms to subject to gene discovery. As outlined in our project management plan, we diverted resources away from the labor intensive fractionation discovery approach as we realized we were not getting novel hits from the screened wild type diversity at the originally targeted frequency (of 1-2 per year).

Subtask B.1-B.3 FY 10 Plans The "primary screening" effort was diminished in FY10 to allow for more concentrated resource allocation on improving the known "weak link" activities in our current enzyme cocktails and to allow for mixture design experiments toward optimizing the ratios of individual proteins in the complex consortium of enzymes. Within crude broths screening, we planned to focus effort on genera of fungi which are phylogenetically similar to those that have given us the best enzyme activities to date, and to carry through screening several high-performing broths, with PNNL scaling up the fermentation of these strains, and providing screening technology for uncovering proteins in the secreted mixtures. Bioinformatic analysis methods and proteomics would be used to identify proteins and genes of interest.

Subtask B.1-B.3 FY 10 Accomplishments. We improved our crude broth screening pipeline in 2010 , to ( 1) more directly focus on discovery of thermostable components and (2) look for synergy with the "next generation" enzyme cocktail, a more active and stable mixture than the CZP00005 mix that serves as our DECREASE benchmark. While previous primary screening efforts had used $50-55{ }^{\circ} \mathrm{C}$, we decided to challenge the collection of organisms by screening cellulolytic broths at $60 \stackrel{\circ}{ } \mathrm{C}$. We found it quite difficult to identify

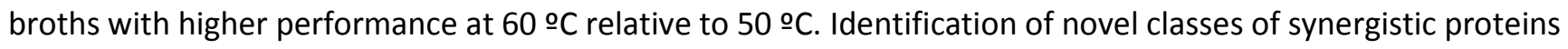
became increasingly difficult as the reference enzyme cocktail already contained highly active components in a number of important enzyme families. In all, about 500 or so broths were screened in the primary screen, including a number of strains which had already been examined, which were retested at the higher temperature. In the second quarter, we received the first large scale fermentation broths from PNNL. Fractionation of these and other broths did not lead to idenification of novel synergistic components. However, the screening work informed us to which candidate organisms would be good sources of candidate genes for the HTM subtask (A.2).

Subtask B.1-B.3 FY 11 Plans. We planned to discontinue primary screening work, allowing a greater focus of resources on improving the known "weak link" activities in our current enzyme cocktails and to allow for mixture design experiments. For secondary screening and broth fractionation activities, we planned to carry through to identification of components in crude broths from previous screens.

Subtask B.1-B.3 FY11 Accomplishments. Less than 250 additional broths were screened in primary screens. Resulting from previous primary screening, upscaled fermentation broths from six organisms were delivered from our collaborators at PNNL for secondary screening. As the material became available in FY11 Q4, these were analyzed during the DECREASE project, but may hold potential for future enzyme improvement. 
DECREASE Final Technical Report, Novozymes Inc. DE-FC36-08G018080

Fractionation of one previously identified fungal broth which had been scaled up in house yielded several boosting fractions when assayed with our HTM (from Task A.2). The proteins in these boosting fractions were analyzed by proteomic methods. At the end of FY11, we had not definitively identified which protein(s) were responsible for enhancing the performance of the HTM.

\section{Subtask B.4. Cloning, expression and characterization of novel biomass active enzymes which are not represented in the current enzyme mixture.}

Under this subtask, we selectively cloned and expressed a wide variety of interesting genes outside of those that we focused on in development of our HTM (Task A.2). Two external collaborators assisted with the subtask (Bernard Henrissat and Jocelyn Rose). The subtask also included sequence generating methods and subsequent "gene mining" activities that were not only central to our discovery of novel components, but also allowed us to uncover CBH Is, CBH IIs, EGs, bGs, xylanases and GH61s from a wide array of organisms. Specifically, we used transposon-assisted signal trapping, cDNA sequencing, and whole genome sequencing. Signal trapping used a proprietary high-efficiency technique for identifying and cloning genes that encode secreted proteins. DNA sequencing eventually dominated our discovery work under this task, as discussed below.

Subtask B.4 FY09 Plans We planned to clone, express, and biochemically characterize at least 100 new biomass active enzymes, including candidates provided by Henrissat's group (based on comparative genomics) and by Rose's group (plant glycoside hydrolases). The new active enzymes would be characterized for basic biochemical properties of these new proteins, as well as for performance in PCS hydrolysis under our application conditions.

Subtask B.4 FY09 Accomplishments While the fraction of insoluble xylan in our PCS is quite low (2.9\%), the finding that xylanase enhanced glucan to glucose conversion led us to explore other hemicellulases components. This was also relevant to our biomass enzyme product development work, as we need to enable efficient conversion of a wide range of substrates, including many with a more substantial and more complex hemicellulose composition relative to DECREASE PCS.

As mentioned in the section on Subtask B.1-B.3 FY09 accomplishments, we began to use results from this activity to prioritize source organisms for cellulase discovery work. At the start of the project, we used signal trapping of secreted genes grown on cellulose to narrow the number of genes to be sequenced. Starting in 2009, we began sequencing of cDNA libraries using Illumina technology; as sequencing costs continued to fall, we increased the number of libraries sequenced in this manner, and eventually sequenced entire fungal genomes in this manner. Direct sequencing became cheaper than our orignial signal trapping methodology during this project.

A slow step in our pipeline of targeted gene discovery has been assembly and anotation of the genes in sequenced libraries. We have focused on improving tools toward making this a faster and more efficient process. Once the genomes are annotated, we prioritize cloning and expression of those components that we believe to be "weakest links."

In FY09, we collaborated with Bernard Henrissat's group to identify novel conserved families with unidentified functions, which we are currently calling "X-domain" families. Some of the X-domain proteins that we 
DECREASE Final Technical Report, Novozymes Inc. DE-FC36-08G018080

analyzed in FY09 showed synergistic effect with the benchmark enzyme system, but none of them could replace an equivalent protein loading of benchmark cellulase.

In addition to X-domain proteins, and known classes of components in the starting enzyme mixture, a handful of other proteins were cloned and expressed and tested, including for example, expansins and various classes of bacterial cellulases that are not present in T. reesei. In FY09, none of these candidates showed synergistic effect with the benchmark enzyme system.

Subtask B.4 F10 Plans. We planned to continue our effort to clone, express, and biochemically characterize various novel putative biomass active enzymes identified thorugh the Henrissat collaboration, as well as from fungal genomes, and also from plant genomes.

Subtask B.4 FY10 Accomplishments Due to improvements in DNA sequencing technologies, cDNA genome sequencing for strains that have demonstrated strong biomass catalytic potential was the choice method for gene discovery. We continued to grow strains under cellulase inducing conditions for cDNA library construction, and sequence using Illumina technology. Methods for improved assembly of genomic reads were developed. Over the year, more than 20 new libraries were sequenced and analyzed. For each organism, a range of 20-50 genes were selected for cloning and expression trials. The majority of components were known enzymes, targeted for candidates in the HTM task. A number of components not present in the monocomponent mixes were cloned and expressed. Also, our collaborative work with the Rose group at Cornell led us to try expression of four GH9 plant genes. Unfortunately, attempts to express the A. oryzae codon optimized synthetic plant genes failed.

Following up on cloning and expressing proprietary genes from the novel X-domain families we had identified in collaboration with Henrissat's lab in 2009, an additional X-domain family was identified, expressed, and characterized.

Subtask B.4 F11 Plans. For targeting cloning and expression, we planned a minimal effort on selection of candidate genes from our screening of GH families not yet represented in our enzyme cocktail. Any novel components capable of boosting the performance of our HTM delivered from Task A would be included in mixture design experiments.

Subtask B.4 FY11 Accomplishments. Effort was focused on leveraging genomic, transcriptomic, and proteomic gene catalogues in attempts to isolate effective HTM components, as well as novel enhancing components, from the organisms that performed best in our extensive broth screening campaign. During FY11, we submitted a total of 57 libraries for Illumina sequencing. After assembly and annotation efforts were completed, we selected on average 20 candidates from each genome for cloning and expression trials. We also developed a high throughput screening method to identify enzymes with high melting temperatures, which can help prioritize which candidates should be purified for secondary screens in preparation for testing with or in place of components in the HTM. As before, the highest priority candidates for testing were those with sequence similarity to components in our current HTM. Outside the HTM GH families, we also tested other components from a range of $\mathrm{GH}$ families and other enzyme classes. We identified a class of boosting components that was not present in the HTM. During the final year of work, we made progress in identifying 
DECREASE Final Technical Report, Novozymes Inc. DE-FC36-08G018080

the best candidates from this class, and defining the requirements for their optimal conference. The best candidate was selected for inclusion in our final validation benchmarking (see Task C).

\section{Task C Results}

The primary goals of Task $\mathrm{C}$ was to coordinate enzyme cost reduction assessment, and deliver progress reports throughout the project.

While the DECREASE deliverable is $2 X$ enzyme dose reduction under the specified assay conditions, coordination with two other activities outside the project are of vital importance to our success of our stated objectives:

(1) assure that enzyme candidates are selected for strain development in order to allow for an enzyme launch of DECREASE components within three years after the close of the project, as targeted in the project objectives,

(2) assure that enzyme candidates allow for cost effective conversion of biomass to sugars on commercially relevant substrates other than NREL PCS, to allow Novozymes to support a goal of broadly enabling biomass refineries

An additional goal for Task $\mathrm{C}$ is to quantify improvements made in enzyme cocktails during FY11. Due to the R\&D timeline, components for final validation benchmarking were selected in 2010, to allow for construction of enzyme production strains. As these validations do not include our best enzyme candidates at the close of the project, we additionally performed comparative testing between our starting enzyme cocktail and the best monocomponent mixture that was in place at the end of FY11. As these are mixtures of monocomponent enzymes, we expect that the performance of $T$. reesei -expressed cocktails of similar composition will be better than the mixtures tested herein.

Task C FY09 Plans. During the first year of work, we aimed to begin our collaborations with external subcontractors. As required under the terms of the award, we planned to coordinate with NREL to allow for an independent audit of the baseline enzyme concentration, enzyme loadings, and yields of enzymatic conversion.

Task C FY09 Accomplishments. In Q1, a protocol for validation testing and future benchmarking of enzyme improvements for DECREASE project was prepared and filed with the NREL audit team. A new lot of NREL PCS for benchmarking and discovery was received. In preparation for the baseline performance validation, trials were performed with both the proposal lot of NREL PCS and the newly received lot of PCS. Early in Q2, the performance validation took place, and we successfully reproduced data showing the baseline enzyme concentration and the required enzyme loadings to achieve target yields of enzymatic conversion on the substrate used in the proposal ("PROPOSAL PCS"). Further, we re-benchmarked our starting enzyme performance on a different lot of NREL PCS (called "DECREASE PCS"), obtaining very similar enzyme loading requirements as for the proposal lot of pretreated corn stover. 
In FY09, before receiving the validation team's report from DOE, we moved forward to carry out a few experiments that had been suggested by the audit team during the validation visit. In one experiment, we found that autoclaving the substrate did not change the amount of the enzymatically released glucose. In addition, we observed that the inclusion of buffer ( $\mathrm{NaOAc} \mathrm{pH} 5.0$ and/or $1 \mathrm{mM} \mathrm{Mn}^{2+}$ in the hydrolysis step does not impact enzymatically released glucose. Based on these results, we maintained the practice of autoclaving substrate to reduce the chance of microbial contamination during set-up and subsequent hydrolysis, and we eliminated buffer and manganese from the reactions for our benchmarking assays through the duration of the project. Finally, we performed experiments to support our earlier assumption that the cellobiose content is negligble in hydrolysates following digestion with very high enzyme doses ("limit digests" or "max digests").

In the third quarter of FY09 we performed our first comparative benchmarking experiment, replacing some of the protein in our starting enzyme mixture (CZPO0005) with top components delivered from Tasks A and B. The enzyme dose required to achieve $90 \%$ conversion was reduced from the CZP00005 loading system by 1.3-fold.

Task C FY10 Plans We planned to select a cocktail from lead candidates that could deliver a 1.5X dose reduction under benchmarking conditions relative to CZP00005 (starting enzyme mixture) on DECREASE PCS.

Task C FY10 Accomplishments. In FY10 Q1, benchmark assays were conducted to measure the enzyme improvements made to date with reference to our benchmarking biomass enzyme cocktail, CZP00005. The improved enzyme composition consisted of a blend of fungal expression broths. The fold reduction in enzyme loading to reach $90 \%$ of enzymatically available glucose (based on theoretical from max digest reactions) for the improved enzyme cocktail is 1.46 -fold, and the fold improvement measured for $80 \%$ conversion was 1.6-fold.

In Q2 of 2010, we received a copy of the NREL validation team's report detailing our initial performance validation. Of the recommended follow up actions that were made in the report, we had already completed and reported on a majority of the items, described above in the FY09 summary. We responded to a recommendation that we reconsider the basis for reporting enzyme loading, in particular whether or not monomeric sugars should be included in the definition of cellulose and xylan equivalents. We noted that in order for units to cancel appropriately in calculations made in the Table B template, the units of measurement for enzyme dose must include all sugar sources, including monomeric sugars present at the onset of hydrolysis. In order to keep the discussion of Table B as simple as possible, we decided to keep our practice of reporting enzyme dose per mg total potential sugar (glucan and xylan, monomers and oligomers). In order to facilitate comparisons with other enzymes, we agreed to also report enzyme doses by a variety of other metrics in our validation reports.

A second recommended follow up action was to validate the accuracy of our limit digest method, and resolve the observed discrepancy between the theoretically obtainable sugars estimated based on chemical composition as compared to measured by high dosage enzymatic digestion. NREL assisted in this follow up by performing a wet chemical compositional assay of our DECREASE PCS, and as a result delivered a revised compositional report to us. We therefore decided in correspondence with the audit team to base our followup actions on comparing our limit digest data with this revised data. In conversations with the audit team, we evaluated a variety of experimental strategies that would probe the validity of our max digest methods. FY10 
experimental results suggested that accounting for changes in the insoluble fraction of solids over hydrolysis would reconcile sugars measured by chemical composition and sugars obtained by our limit digest method.

Task C FY11 Plans The key goal was to deliver a 2X dose reduction under benchmarking conditions relative to CZP00005 (starting enzyme mixture) on DECREASE PCS. We also planned to update the NREL validation team, and DOE, regarding an improvement to our HPLC analytical method, allowing reconciliation between max digest available sugars, and NREL's chemical composition.

\section{Task C FY11 Accomplishments}

Mass balance closure. Our original method entailed sampling reactions with dilutions performed by volume after a liquid/solid separation. We improved this method, diluting instead by weight prior to liquid/solid separation, with density measurements of each reaction. Based on the new methodology, we observed that a high enzyme dose (limit digest conditions, $50 \mathrm{mg}$ unformulated Cellic ${ }^{\circledR} \mathrm{CTec} 2 / \mathrm{g}$ cellulose +glucose + xylan + xylose) yields an average of $96 \%$ of the total cellulose + glucose in the composition to glucose (average based on 6 experiments). We analyzed residual solids remaining after a limit digest, and found that inclusion of residual glucan in the undigested material allowed closure of the mass balance on a glucan basis to $99 \%$. On a xylan basis, we obtained an average $94 \%$ conversion of the total xylan plus xylose in the material during a limit digest, and closed the mass balance on a xylan basis to $98 \%$ after analysis of xylan in the residual pellet remaining after hydrolysis. The improved protocols and resulting data were shared with the validation team and documented in our validation report.

FY 11 Benchmarking prior to final validation. Strain construction, incorporating lead Task A candidates from 2010, screening for optimal expression levels of novel components, scale up of enzyme production at pilot and full scale production, and QC development for launch were all accomplished outside of DECREASE. The strain development and pre-launch activities satisfied our need for T. reesei-expressed components, required to obtain optimal activity, and also ensured that we are able to commercialize DECREASE enzymes (ahead of the targeted date, which was three years after the close of the project), fulfilling a key objective.

During the course of 2011, we incorporated newly discovered components into enzyme mixtures in order to perform benchmarking experiments. A benchmarking assay in Q2 demonstrated a 1.96-fold reduction in enzyme loading to reach $90 \%$ conversion for the improved cocktail run at 55 ㄷ compared to the original cellulase mix (CZP00005) at 50 ㄷ. A similar fold reduction was required to convert $80 \%$ of cellulose and xylan to monomers. In Q3, we ran several more trials with this cocktail, but found that performance of a single component in the mixture was unreliable under these assay conditions, leading to lower fold imrpovements in the benchmarking.

In Q4 FY11, we performed benchmarking experiments to compare the performance of a precommercial enzyme cocktail at $55{ }^{\circ} \mathrm{C}$ to our DECREASE baseline enzyme (CZP00005) at 50 ㅇ. In the first experiment a greater than $2 X$ dose reduction was achieved. In the second experiment, the dose reduction measured was less than $2 X$. Potential sources of variability, which may explain the disparate results, are discussed below (see "Problems with $50 \mathrm{~g}$ assay"). 
Final Validation. Precommercial CTec3 cocktail, along with an additional component, was tested in two separate experiments, one prior to a validation visit from DOE and NREL team members, and the second during the validation visit (Nov 30-Dec 8, 2011). The enzyme performance was compared to CZP00005 (starting enzyme preparation), and hydrolysis on DECREASE PCS was tested under benchmark conditions (7 days, $21.5 \%$ TS, pH 5, 50 g assay). Enzyme preps were tested at temperatures that were thought to be optimal for their performance ( 50 ㅇ C for benchmark, 54 ㄷ C for improved enzyme mix). We measured enzyme loadings $\left(E_{L}\right)$ required to achieve conversion on a "total potential glucose" basis, e.g., cellulose + glucose to monomer conversion basis. The $E_{L}$ for the original conversion target of $90 \%$ was measured, and as we have found that ethanol production costs and enzyme costs per gallon are lower when $80 \%$ conversion is targeted, we also measured the $E_{L}$ for this target as well. Comparing the two experiments, the benchmark enzyme (CZP00005) performed quite similarly in each of the separate runs (Figure 5), while there was slightly more scatter in sample points for biomass conversion measured for the improved enzyme mix. The variability of the replicate samples, combined with the low slope of the curves as they approach maximum conversion led to measurement of different enzyme loadings for each of the individual experiments. Based on the two experiments, using all available data, the improvement factor is 1.78 -fold for $90 \%$ conversion, and 1.81-fold for $80 \%$ conversion (Figure 6). 


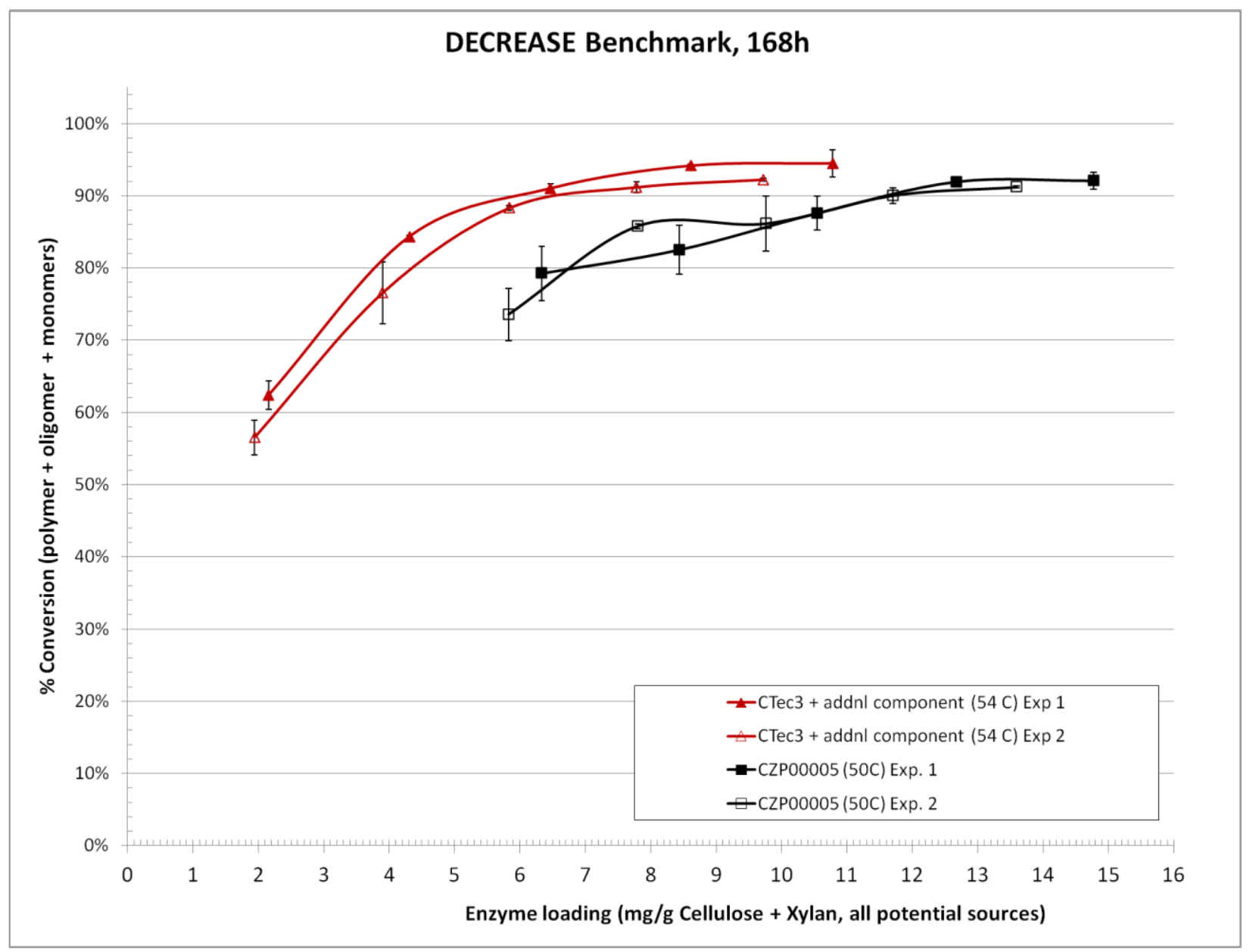

Figure 5: Final Validation comparison on starting enzyme $(50 \stackrel{\circ}{ })$ and improved enzyme (54 $\left.{ }^{\circ} \mathrm{C}\right)$ performance in PCS hydrolysis during two separate experiments. The reactions were $50 \mathrm{~g}$ scale, run at $21.5 \%$ TS, 7 day hydrolysis. Plotted is the mean and standard deviation of mean for both data sets. Note that small differences at $90 \%$ conversion of improved enzyme mix result in significant changes in fold improvement. 


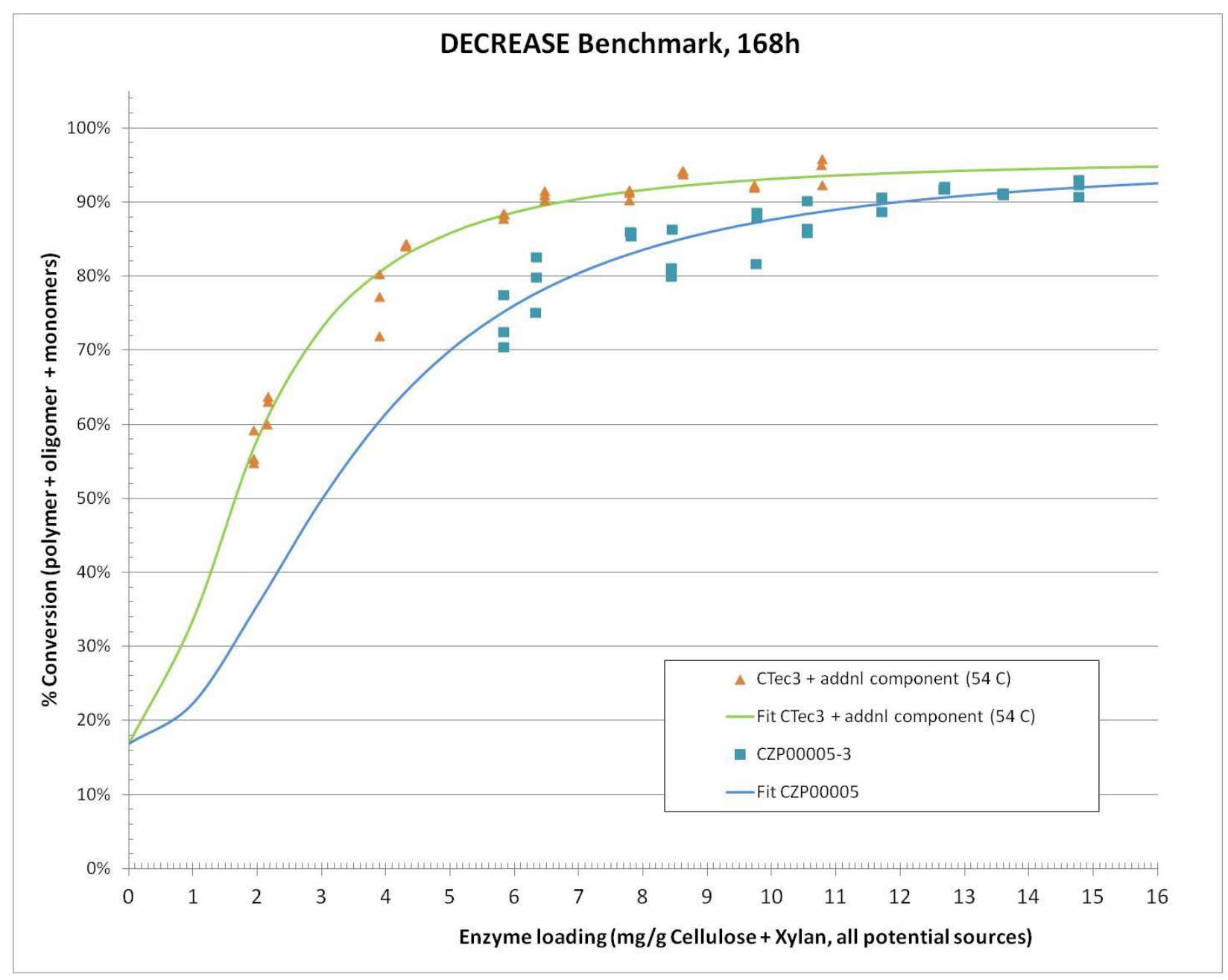

Figure 6: Final Validation comparison on starting enzyme $(50 \stackrel{\circ}{\circ})$ and improved enzyme ( $54 \stackrel{\circ}{\circ})$ performance in PCS hydrolysis, with fitted curves from combination of two separate experiments. The reactions were $50 \mathrm{~g}$ scale, run at $21.5 \% \mathrm{TS}, 7$ day hydrolysis.

\section{Problems with $50 \mathrm{~g}$ assay}

We had difficulty during the final year of work in obtaining reproducible results from the benchmark $50 \mathrm{~g}$ shake flask assay. One cause of variability is use of a class of new enzymes, for which optimal conditions are not yet fully understood; variability in performance of these enzymes was also observed in other assay formats. However, we observed variability even when the new class of enzymeenzymes were not included (as noted in FY2011 Accomplishments section above, we did not see good reproducibility even when the CTec3 precommercial cocktail was tested alone in Q4. CTec3 performance was more reproducible in other assay formats.

A suspected cause of flask to flask variability is poor mixing, and a problem with hydrolysate (and in particular undigested solids) getting trapped on the sides of the $125 \mathrm{~mL}$ Erlenmeyer flasks. During loading of solids, and transfer to incubators, PCS material occasionally sticks to the flask, and during the 7 day reaction, remains out of solution, preventing enzyme from accessing the material. 
DECREASE Final Technical Report, Novozymes Inc. DE-FC36-08G018080

A second concern is that the assay is not very precise in predicting enzyme dose at very high conversion targets. The slope of enzyme dose vs. conversion curves is very gradual in the region from $80 \%$ to $95 \%$ conversion. As the $7 \mathrm{~d}$ dose response curve becomes very flat in this region, very small changes in observed sugars (within the standard experimental error of the method) have large impact on the required enzyme dose $\left(E_{L}\right)$ that is calculated using curves fit to the data. This is apparent in Figure 5, where differences at $90 \%$ conversion of improved enzyme mix run in two independent experiments results in significant changes in calculated fold improvement.

\section{Validation of CTec3 performance on DECREASE in a kettle reactor, at $50{ }^{\circ} \mathrm{C}$}

As we were not satisfied with the reproducibility of the $50 \mathrm{~g}$ assay, we decided to additionally measure performance in a larger scale lab assay, which is superior to the flask based assay in that it more closely approximates industrial scale reactors. We have seen good reproducibility between kettle scale hydrolysis and pilot scale reactors with regard to enzymatic dose requirement. Specifically, we utilized $500 \mathrm{~mL}$ kettle reactors, using an IKA agitation motor to provide effective mixing.

While maintaining methodology from our DECREASE protocols as much as possible, we repeated the experiment run during our validation reaction in kettle, with two caveats. First, we decided to focus on the performance of CTec3 alone without additions. Second, we changed the temperature of the assay. The selection of 54 o $\mathrm{C}$ was based on the best available data we had at the time; we later realized that this may have been too high for optimal enzyme performance. We had previously selected this temperature based on optima observed for a corresponding blend of HTM components, run at a shorter time frame, also based on limited experiments with the $T$. reesei produced enzyme under DECREASE assay conditions. As more data became available from our enzyme launch team and application development unit, we realized that $50 \stackrel{\circ}{ } \mathrm{C}$ is the optimal temperature for $\mathrm{CTec} 3$ in a $7 \mathrm{~d}$ hydrolysis.

Figure 7 shows the performance of $\mathrm{CTec} 3$, compared to the CZP00005 starting enzyme cocktail, both run at 50 oc. The reaction scale is increased from $50 \mathrm{~g}$ to $500 \mathrm{~g}$; total solids are $21.5 \%, 7 \mathrm{~d}$ hydrolysis, as for the $50 \mathrm{~g}$ assay. HPLC analysis and curve fitting were performed as for the standard (50 g) DECREASE benchmark assay. In the kettle experiment, $\mathrm{E}_{\mathrm{L}}$ for CZP00005 conversion of $80 \%$ of the cellulose + glucose in the substrate to monomer required $5.54 \mathrm{mg} / \mathrm{g}$ cellulose +glucose +xylan +xylose, compared to $6.9 \mathrm{mg} / \mathrm{g}$ gcellulose +glucose +xylan +xylose for the same target with this same enzyme in the benchmark $50 \mathrm{~g}$ assay. Interestingly, the CZP00005 enzyme $E_{L}$ for $90 \%$ conversion in kettle was $11.2 \mathrm{mg} / \mathrm{g}$ cellulose +glucose +xylan +xylose, compared to $12 \mathrm{mg} / \mathrm{g}$ cellulose +glucose +xylan +xylose measured for the $90 \%$ target in the $50 \mathrm{~g}$ assay.

The fold-improvement for CTec3 over CZP00005 in kettle at the $80 \%$ conversion target is $1.89 \mathrm{X}$, calculated from the CTec $E_{L}$ of $2.93 \mathrm{mg} / \mathrm{g}$ cellulose +glucose +xylan +xylose. As can be seen in Figure 7, the CTec3 curve is very flat in the area of $90 \%$ conversion (flatter than observed for the shake flask based assay), which gives an $E_{L}$ of $7.15 \mathrm{mg} / \mathrm{g}$ cellulose +glucose +xylan +xylose for $90 \%$ conversion, resulting in a 1.54X dose reduction over the starting enzyme cocktail. 


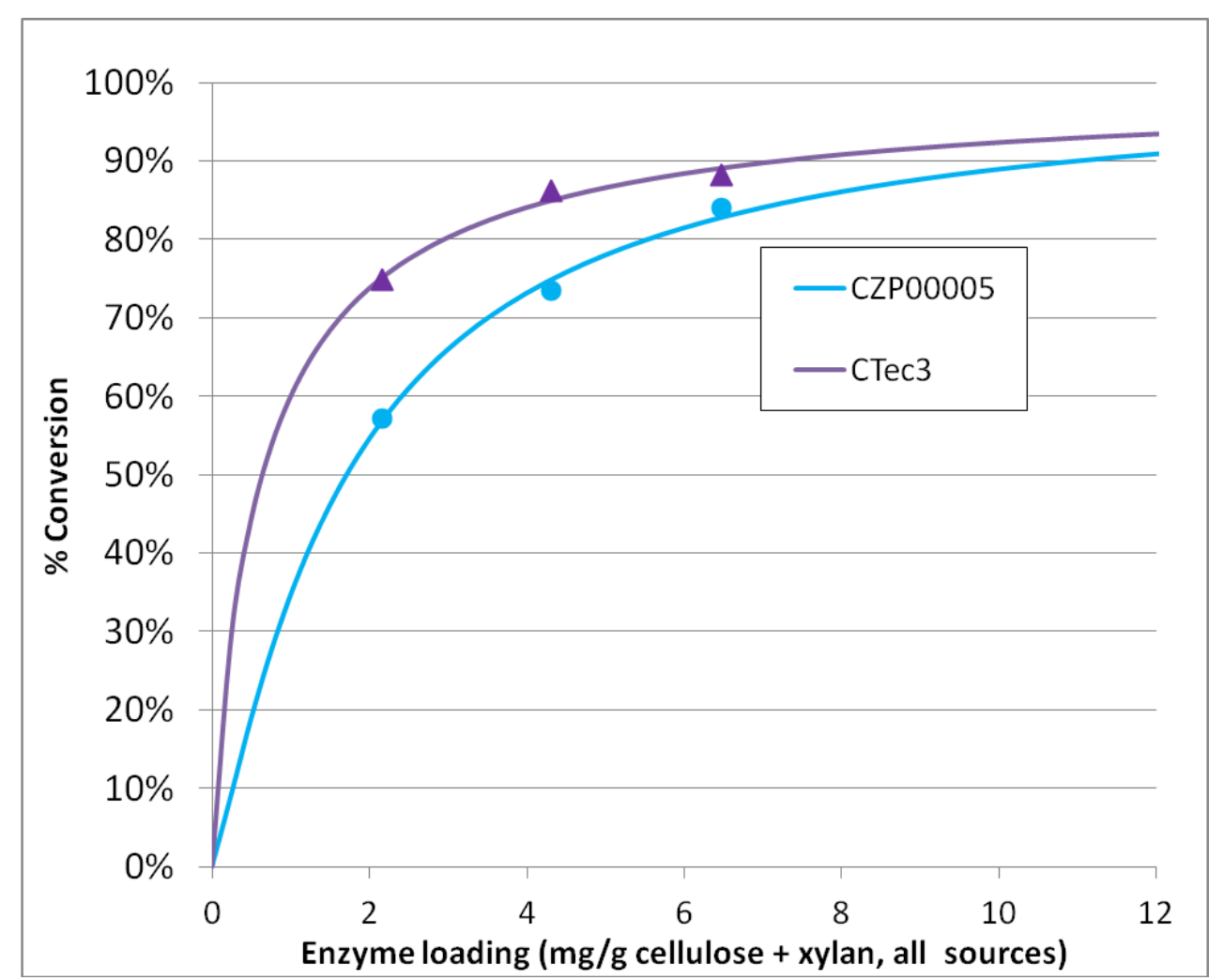

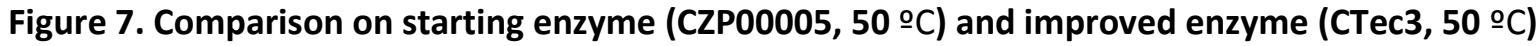
performance in PCS hydrolysis, in kettle reactor. Substrate was unwashed DECREASE PCS. The reactions were $500 \mathrm{~g}$ scale, run at $21.5 \%$ TS, 7 day hydrolysis. For $80 \%$ conversion, a $1.89 \mathrm{X}$ dose reduction is observed for CTec3 relative to CZP00005.

\section{Assessing overall project fold improvements, including HTM candidates not present in final validation}

As has been noted several times in this report, the benchmarked enzyme cocktail does not include our current best performing enzyme candidates. Specifically, work performed during FY11 led to identification of superior protein molecules that are not present in the CTec3 cocktail. We wished to capture the trajectory of improvement for the entire project, not just 2009-2010, realizing that expression of the 2011 candidates in $T$. reesei at optimal levels would likely lead to a better fold-improvement than that previously reported from final validation and kettle assay of CTec3.

As the 2011 components have not yet been moved to production strains, the quantities available for testing are still limited. We therefore evaluated the relative performance of our "best" FY11 HTM relative to CZP00005 by using our high solids mini-assay, which was discussed under Task A.2 accomplishments (FY11). This allowed us to compare performance of enzyme cocktails under rigorous conditions where high concentrations of soluble inhibitors and high levels of substrate are present.

Figure 8 shows dose response curves for the starting enzyme run at its optimal temperature (50 $9 \mathrm{C}), \mathrm{CTec} 3$ at $50 \stackrel{\circ}{\circ}$ (as evaluated in kettle, and also part of the mixture that was validated by the NREL-DOE team in Dec 
2011), and finally with comparison to the best performing monocomponent mix run at its optimal temperature $(60 \circ \mathrm{C})$. It can be seen that the enzyme doses required for conversion in this assay format are higher than the levels measured for the better mixed shake flask assay, and the most industrially relevant kettle assay.

However, looking at the relative differences in the required doses gives an indication of the relative performance diffrences between the cocktails. The fold-improvement in enzyme doses required to achieve $80 \%$ and $90 \%$ conversion, relative to the CZP00005 dose, is shown in Table 1.

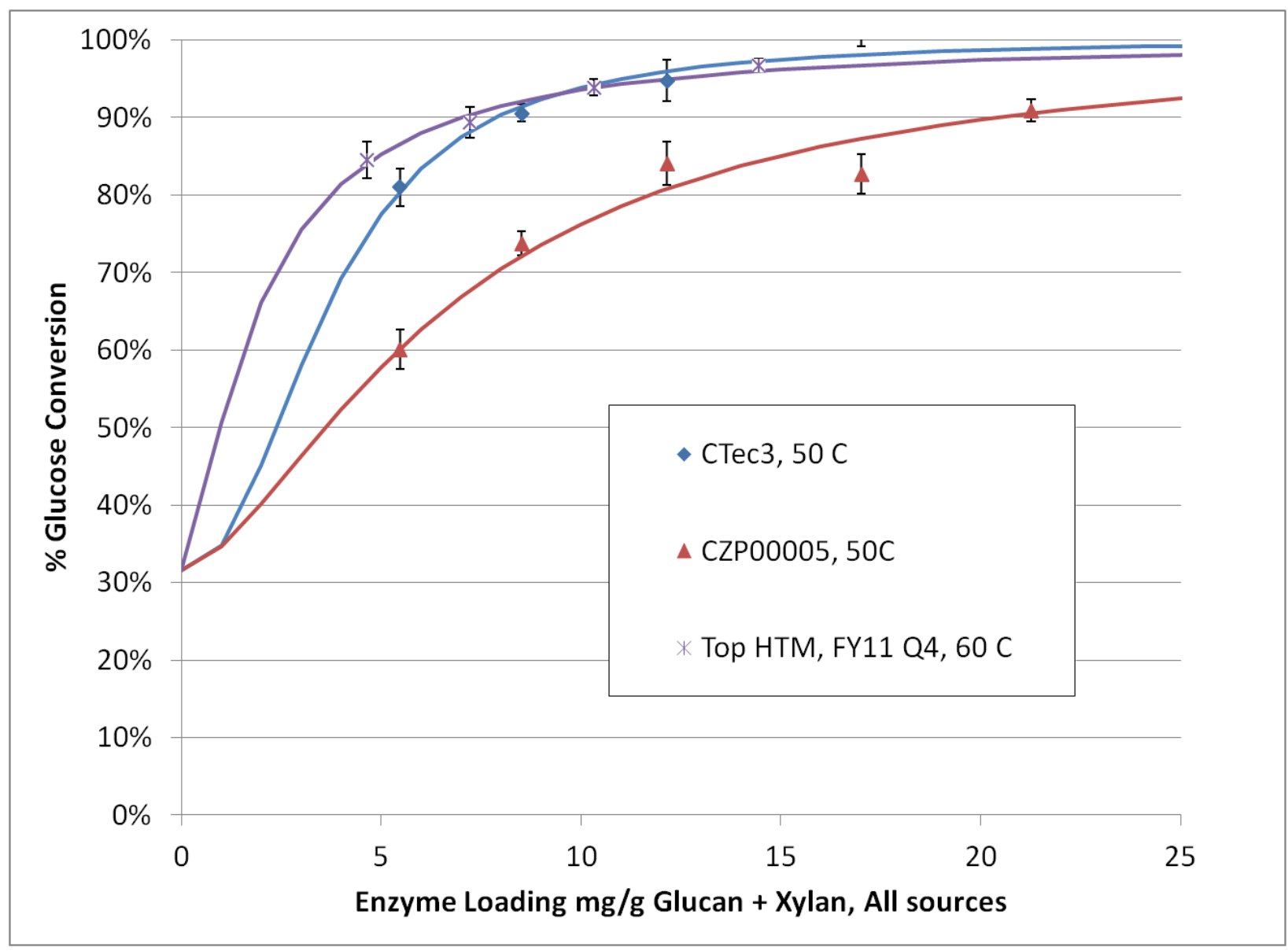

Figure 8. Comparison on starting enzyme (CZP00005, 50 ㄷ), improved enzyme (CTec3, 50 으) from our validation, and the top high temperture monocomponent mix available at the close of the project (Top HTM FY11 Q4, 60 ㅇ), run in a high solids mini assay. Substrate was unwashed DECREASE PCS. The reactions were $225 \mathrm{uL}$ scale, run at $21.5 \%$ TS, 7 day hydrolysis. For each sample, 4 duplicates were run and standard deviation is plotted.

\begin{tabular}{|l|l|l|}
\hline & $\begin{array}{l}\text { Fold Improvement over CZP00005, 50 ㄷ } \\
\text { at 80\% Conv }\end{array}$ & $\begin{array}{l}\text { Fold Improvement over CZP00005, 50 } \\
\text { at 90\% Conv }\end{array}$ \\
\hline CTec 3 (50 ㄷ) & 2.19 & 2.60 \\
\hline Top HTM FY11 Q4 $(60$ C) & 3.16 & 2.92 \\
\hline
\end{tabular}

Table 1: Fold-improvement observed in high solids mini assay between CZP00005 (50 C) and CTec3 (50 C) and the top performing monocomponent HTM from Q4 FY11 (60 ㄷ). 


\section{Conclusion: actual accomplishments compared with original goals and objectives}

Based on final validation experiments and the upscaled kettle hydrolysis experiment, CTec3 delivers a 1.8-1.9X dose reduction for $80 \%$ conversion of all sources of cellulose and xylose, on DECREASE PCS, when run on application relevant whole slurry substrate at high solids loadings ( $21.5 \% \mathrm{TS})$. While the measured performance improvement falls slightly short of the targeted goal of $2 \mathrm{X}$ dose reduction, the $\mathrm{CTec} 3$ composition does not include the best available enzyme components from the DECREASE effort. Experimental mixtures containing the top components that were assayed in a smaller scale assay, but with conditions otherwise similar to those used in the official benchmarking indicated that newer mixtures required $2.9 \mathrm{X}$ less enzyme for $90 \%$ conversion, and $3.2 \mathrm{X}$ less enzyme for $80 \%$ conversion, relative to the starting enzyme cocktail. The experimental mixture comparisons reveal that Novozymes is in a strong position to continue enzyme based improvements that will further drive down costs.

Our initial goal was to commercialize an improved cocktail within 3 years of the end of the project. We surpassed that goal with our February 2012 launch of CTec3, a multi-enzyme cocktail derived in part from components developed under DECREASE, which occurred 6 months after the close of the project. While the results are not shown in this report, we have publicly demonstrated that the improvements over previous generation products are observed on a range of pretreated substrates, including agricultural residues, woods from various sources, and municipal solid waste. This shows that while our benchmarking reports improvements on a single lot of pretreated corn stover, our enzyme discovery and development program delivers a product that is efficient across feedstocks and pretreatments. 


\title{
Products developed
}

\author{
Cellic ${ }^{\circledR} \mathrm{CTec}^{3}$ and $\mathrm{Cellic}^{\circledR} \mathrm{HTec}^{3}$
}

\section{Publications}

Paul Harris, Stimulation of lignocellulose hydrolysis by proteins of glycoside hydrolase family 61 (GH61): A protein family in search of a function, Keystone Symposia - The Future of Biofuels, Oral Presentation.

Snowbird, Utah, April 4-8, 2009.

Feng Xu, Kinetic difference of soluble and adsorbed cellulases, Poster VIII European Symposium of The Protein Society, June 14-18, 2009, Zurich, Switzerland.

Elena Vlasenko, Improved cellulase compositions for lignocellulose hydrolysis. 31st Symposium on Biotechnology for Fuels and Chemicals, Poster, May 3-6, 2009, San Francisco

Romil Benyamino, Hanshu Ding, Biochemical characterization of family 6 and 7 exo-cellobiohydrolases, Poster.31st Symposium on Biotechnology for Fuels and Chemicals, May 3-6, 2009, San Francisco Ani Tejirian, Feng Xu, Mechanistic Study of Enzymatic Cellulolysis Inhibition, 31st Symposium on Biotechnology for Fuels and Chemicals, Poster. May 3-6, 2009, San Francisco

Paul Harris, Redesigning the Trichoderma reesei secretome for enhanced lignocellulose degradation, Synthetic Biology Workshop, Oral Presentation. 23-25 July 2009, Berkeley, CA

Jason Quinlan, Improving enzymatic cellulose hydrolysis: effects of non-cellulose components of biomass feedstock. GRC: Cellulosomes, Cellulases \& other Carbohydrate Modifying Enzymes. Oral Presentation. July 2631, 2009, Andover, NH

Matt Sweeney, Improving the composition of microbial cellulase mixtures for increased biomass hydrolysis at lower protein loadings. 60th Annual Meeting of the Society for Industrial Microbiology (SIM), Oral Presentation. July 29-30, 2009, Toronto, Canada

Claus Crone Fuglsang, Novozymes perspectives on B2E, IEA Bioenergy Conference, Aug 23-26, 2009, Oral Presentation. Vancouver, Canada

Hanshu Ding, Enhanced Enzymatic Biomass Conversion to Fermentable Sugars and Ethanol, 238th American Chemical Society Meeting, Oral Presentation. Aug 20, 2009, Washington DC

Sarah Teter, Biological conversion of next generation feedstocks, Next Generation Biofuel Feedstocks Conference, Oral Presentation. Nov 16, 2009, San Francisco, CA

Paul V.Harris, Ditte Welner, K. C. McFarland, Edward Re, Jens-Christian Navarro Poulsen, Kimberly Brown, Rune Salbo, Hanshu Ding, Elena Vlasenko, Sandy Merino, Feng Xu, Joel Cherry, Sine Larsen and Leila Lo Leggio (2010) Stimulation of Lignocellulosic Biomass Hydrolysis by Proteins of Glycoside Hydrolase Family 61:

Structure and Function of a Large, Enigmatic Family. Biochemistry 49(15):3305-3316

R. Benyamino, and H. Ding, Biochemical Characterization of Family 6 and 7 Exo-cellobiohydrolases. Poster presentation at the $32^{\text {nd }}$ Symposium on Biotechnology for Fuels and Chemicals, Clearwater, FL, Apr 19-22, 2010 
DECREASE Final Technical Report, Novozymes Inc. DE-FC36-08G018080

Paul Harris, Recent progress in development of cost-effective enzymes for degradation of lignocellulosic biomass, oral presentation at the 32nd Symposium on Biotechnology for Fuels and Chemicals, Clearwater Florida. Oral Presentation. April 19-22, 2010

L. Murphy, MJ. Baumann, K Borch, M. Sweeney, P Westh. (2010) An enzymatic signal amplification system for calorimetric studies of cellobiohydrolases Anal Biochem. 404(2):140-148

Z Yu, Discovery of Novel Industrial Enzymes - Genomics Approach. Presentation at BIT's Inaugural Symposium on Enzymes \& Biocatalysis-2010, Shanghai, China, Apr 22-24, 2010.

Feng Xu, Ani Tejirian; Cellulase Inhibition by Mono-and Polymeric Amino Acids; 25th International Carbohydrate Symposium; Poster. August 1- 6, 2010; Tokyo, Japan

Shaghasi, Tarana; Sweeney, Matt; Vlasenko, Elena, Improving cellulase compositions for lignocelluloses hydrolysis ACS $240^{\text {th }}$ National Meeting, poster. August 23, 2010, Boston

Sarah Teter, Sustainably Produced Sugars From Biomass: The Key to Commercialization. Oral Presentation, AICHE Annual Meeting, Oral Presentation. 10 Nov, 2010 Salt Lake City, UT

Sarah Teter, Enzymes for biofuel production from biomass: Novozymes' cross-cutting technology enables commercialization of cellulosic ethanol, Oral Presentation, Pacific Rim Summit on Industrial Biotechnology and Bioenergy, Oral Presentation. Dec 11, 2010, Honolulu, Hawaii.

Fuglsang, Claus Crone. Cellulosic Ethanol - A Novozymes Perspective. UC Davis Seminar in Dep. of Biological and Agricultural Engineering, Davis, CA, Oral Presentation. 24 January, 2011

Harris, Paul V. Development of a cost-effective enzymatic solution for lignocellulose degradation: The Novozymes Reality Show. Energy Biosciences Institute Spring 2011 Seminar Series, UC Berkeley, Berkeley CA, Oral Presentation. 25 January, 2011

Praestgaard. E, Elmerdahl J, Murphy L, Nymand S, McFarland KC, Borch K, West P. A kinetic model for the burst phase of processive cellulases. FEBS Journal Article first published online: 28 MAR 2011 DOI: 10.1111/j.17424658.2011.08078.x

Mark Wogulis. Enzyme Development for Biofuel Production from Cellulosic Biomass: Application of Advanced technology to Enable the Biorefinery. CIFAR Conference XXIX: Biofuels - A Global Pipeline, Davis, CA, Oral presentation. April 4, 2011

Zhang Yu. Unlock Magic of Nature for Industrial Enzymes-Genomics and Proteomics Approach. BIT's 2nd Inaugural Symposium on Enzymes \& Biocatalysis-2011 (SEB-2011), Dalian, China, Oral presentation. April 2529, 2011.

Hanshu Ding and Romil Benyamino. Biochemical Characterization of Endoglucanases from Different GH Families. $33^{\text {rd }}$ Symposium on Biotechnology for Fuels and Chemicals. Seattle, WA, Poster presentation. May 25, 2011. 
DECREASE Final Technical Report, Novozymes Inc. DE-FC36-08G018080

Brett McBrayer. Poster presentation. Improved enzyme mixtures for high temperature saccharification of lignocellulosic biomass. 33rd Symposium on Biotechnology for Fuels and Chemicals. Seattle, WA, May 2-5, 2011.

Katja Salomon Johansen and Matt Sweeney. Function GH61 enzymes in biomass deconstruction. $33^{\text {rd }}$ Symposium on Biotechnology for Fuels and Chemicals. Seattle, WA, Oral presentation. May 2-5, 2011.

Elena Vlasenko. Improved enzyme mixtures for high temperature saccharification of lignocellulosic biomass. BIO World Congress on Industrial Biotechnology and Bioprocessing, Toronto, Oral presentation. May $8-11$, 2011.

Paul Harris. Development of a cost-effective enzymatic solution for lignocellulosic biomass degradation. NSERC Bioconversion Network Annual General Meeting. University of Toronto, Oral presentation. June 6-8, 2011.

Janine Lin, Enzyme development for biofuel production from cellulosic biomass: Application of advanced technology to enable the biorefinery. IUMS 2011, Sapporo, Japan, September 6-10, Oral Presentation. 2011.

Feng Xu. Plurality of $\beta-1,4$-endoglucanase in microbial cellulose-degrading enzyme machinery,43rd IUPAC World Chemistry Congress, San Juan, Puerto Rico, Poster. July 31 to Aug 5, 2011

Matt Sweeney. The function of GH61 proteins in cellulose depolymerization. Gordon research conference, Cellulosomes, Cellulases \& Other Carbohydrate Modifying Enzymes, Stonehill College, Easton, MA, Oral Presentation. Jul 19, 2011

James A. Langston, Tarana Shaghasi, Eric Abbate, Feng Xu, Elena Vlasenko, and Matt D. Sweeney. Oxidoreductive Cellulose Depolymerization by the Enzymes Cellobiose Dehydrogenase and Glycoside Hydrolase 61" Applied and Environmental Microbiology, 2011, 77 (19):7007-7015

Katja Salomon Johansen. Polysaccharide active enzymes - tools for the development of advanced and sustainable products. EPNOE Wageningen, NL, Oral Presentation. Sep 1, 2011

Katja Salomon Johansen. Recent developments in the understanding of enzymatic decomposition of cellulose. 2nd Conference on lignocellulosic ethanol, Verona, IT Oral Presentation Oct 12, 2011

R. Jason Quinlan, Matt D. Sweeney, Leila Lo Leggio, Harm Otten, Jens-Christian N. Poulsen, Katja Salomon Johansen, Kristian B. R. M. Krogh, Christian Isak Jørgensen, Morten Tovborg, Annika Anthonsen, Theodora Tryfona, Clive P. Walter, Paul Dupree, Feng Xu, Gideon J. Davies, Paul H. Walton. Insights into the oxidative degradation of cellulose by a copper metalloenzyme that exploits biomass components" Proceedings of the National Academy of Sciences, USA. Sep 13, 2011, 108(37):15079-15084

James A. Langston, Kimberly Brown, Feng Xu, Kim Borch, Ashley Garner, Matt D. Sweeney. Cloning, expression and characterization of a cellobiohydrolase dehydrogenase from Thielavia terrestris induced under cellulose growth conditions. Biochimica et Biophysica Acta (BBA)-Proteins \& Proteomics. Available online 30 March 2012 (http://www.sciencedirect.com/science/article/pii/S1570963912000568) 


\section{Networks of collaborations fostered}

The collaboration with Bernard Henrissat's group under DECREASE strengthened a key strategic partnership between Novozymes and the leading glycoside hydrolase research group at CNRS. The work on fermentation upscaling and assay development that was delivered by PNNL researchers helped develop a connection between Novozymes' biomass enzyme researchers and this cutting edge fungal biotechnology lab. Finally, a new collaboration with Joss Rose's group at Cornell connected researchers with expertise in glycoside hydrolases from microbes with researchers having expertise in the same enzymes in plants.

\section{Web site or other internet sites that reflect the results of the project}

Cellic ${ }^{\circledR}$ CTec3 launch press releases reflect results from DECREASE, as this commercial cocktail contains enzyme components that were developed under the project.

http://www.bioenergy.novozymes.com/ 
DECREASE Final Technical Report, Novozymes Inc. DE-FC36-08G018080

\section{Inventions/Patent applications:}

\begin{tabular}{|c|c|c|c|c|c|c|}
\hline $\begin{array}{l}\text { Family } \\
\text { No. }\end{array}$ & Case Reference & Filing & Filing Number & Grant & Grant No. & Remarks \\
\hline \multirow[t]{5}{*}{11462} & \multicolumn{5}{|c|}{ Title: Compositions for saccharification of cellulosic material } & \\
\hline & \multicolumn{5}{|c|}{$\begin{array}{l}\text { Inventors: } \\
\text { McBrayer, Brett (BMBy) } \\
\text { Shaghasi, Tarana (TSHG) } \\
\text { Vlasenko, Elena (EIVI) } \\
\end{array}$} & \\
\hline & 11462-US-NP & 05 Nov 2010 & $12 / 940,952$ & & & \\
\hline & 11462-US-PRO & 06 Nov 2009 & $61 / 259,014$ & & & \\
\hline & 11462-WO-PCT & 05 Nov 2010 & PCT/US10/55723 & & & \\
\hline \multirow[t]{11}{*}{11573} & \multicolumn{5}{|c|}{ Title: Polypeptides having acetyl xylan esterase activity and polynucleotides encoding same } & \\
\hline & \multicolumn{5}{|c|}{$\begin{array}{l}\text { Inventors: } \\
\text { Börjesson, Johan (JBso) } \\
\text { Hansen, Peter Kamp (PKH) } \\
\text { Viks } \varnothing-N i e l s e n, \text { Anders (AVNi) }\end{array}$} & \\
\hline & 11573-BR-PCT & 23 Mar 2010 & & & & \\
\hline & 11573-CA-PCT & 23 Mar 2010 & & & & \\
\hline & $11573-\mathrm{CN}-\mathrm{PCT}$ & 23 Mar 2010 & 201080013739.6 & & & \\
\hline & 11573-IN-PCT & 23 Mar 2010 & 7466/CHENP/2011 & & & \\
\hline & 11573-EP-EPT & 23 Mar 2010 & 10710035.6 & & & \\
\hline & 11573-EP-EPA & 24 Mar 2009 & 09155966.6 & & & \\
\hline & 11573-US-PCT & 23 Mar 2010 & $13 / 145,377$ & & & \\
\hline & 11573-US-PRO & 02 Apr 2009 & $61 / 166,061$ & & & \\
\hline & 11573-WO-PCT & 23 Mar 2010 & PCT/EP10/053770 & & & \\
\hline \multirow[t]{4}{*}{11587} & \multicolumn{5}{|c|}{ Title: Polypeptides having cellobiohydrolase activity and polynucleotides encoding same } & \\
\hline & \multicolumn{5}{|c|}{$\begin{array}{l}\text { Inventors: } \\
\text { Abbate, Eric (EAbb) } \\
\text { Brown, Kimberly (KMBr) } \\
\text { Spodsberg, Nikolaj (NSpo) }\end{array}$} & \\
\hline & 11587-US-PRO & 29 Oct 2009 & $61 / 256,074$ & & & \\
\hline & 11587-WO-PCT & 28 Oct 2010 & PCT/US10/054484 & & & \\
\hline \multirow[t]{10}{*}{11603} & \multicolumn{5}{|c|}{ Title: Polypeptides having xylanase activity and polynucleotides encoding same } & \\
\hline & \multicolumn{5}{|c|}{$\begin{array}{l}\text { Inventors: } \\
\text { Abbate, Eric (EAbb) } \\
\text { Brown, Kimberly (KMBr) } \\
\text { Maranta, Michelle (MMar) }\end{array}$} & \\
\hline & 11603-BR-PCT & 22 Apr 2010 & & & & \\
\hline & 11603-CA-PCT & 22 Apr 2010 & & & & \\
\hline & $11603-\mathrm{CN}-\mathrm{PCT}$ & 22 Apr 2010 & & & & \\
\hline & 11603-EP-EPT & 22 Apr 2010 & & & & \\
\hline & $11603-I N-P C T$ & 22 Apr 2010 & $8473 /$ CHENP/2011 & & & \\
\hline & 11603-US-NP & 22 Apr 2010 & $12 / 765,358$ & & & \\
\hline & 11603-US-PRO & 30 Apr 2009 & $61 / 174,237$ & & & \\
\hline & 11603-WO-PCT & 22 Apr 2010 & PCT/US10/032034 & & & \\
\hline
\end{tabular}




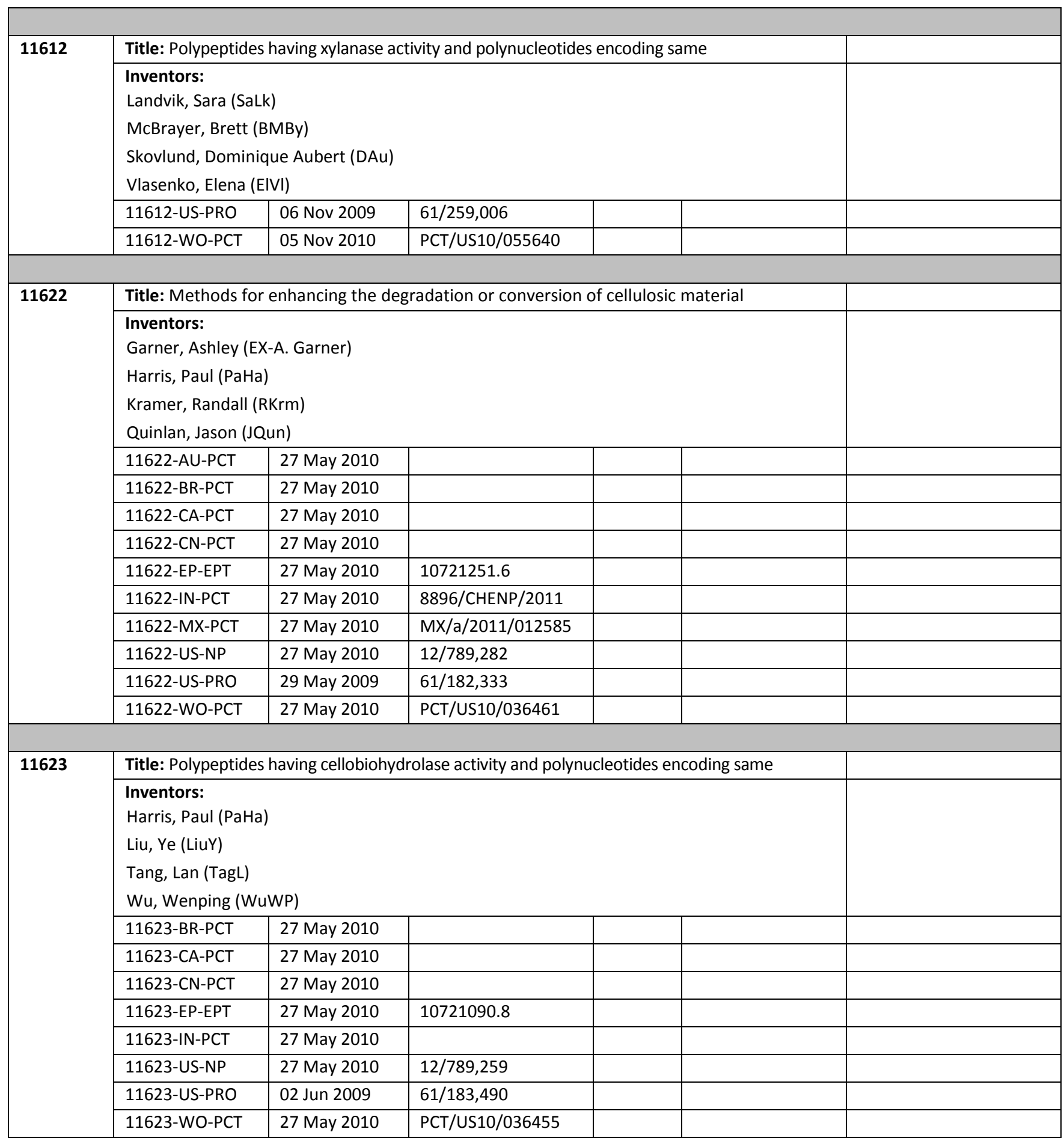




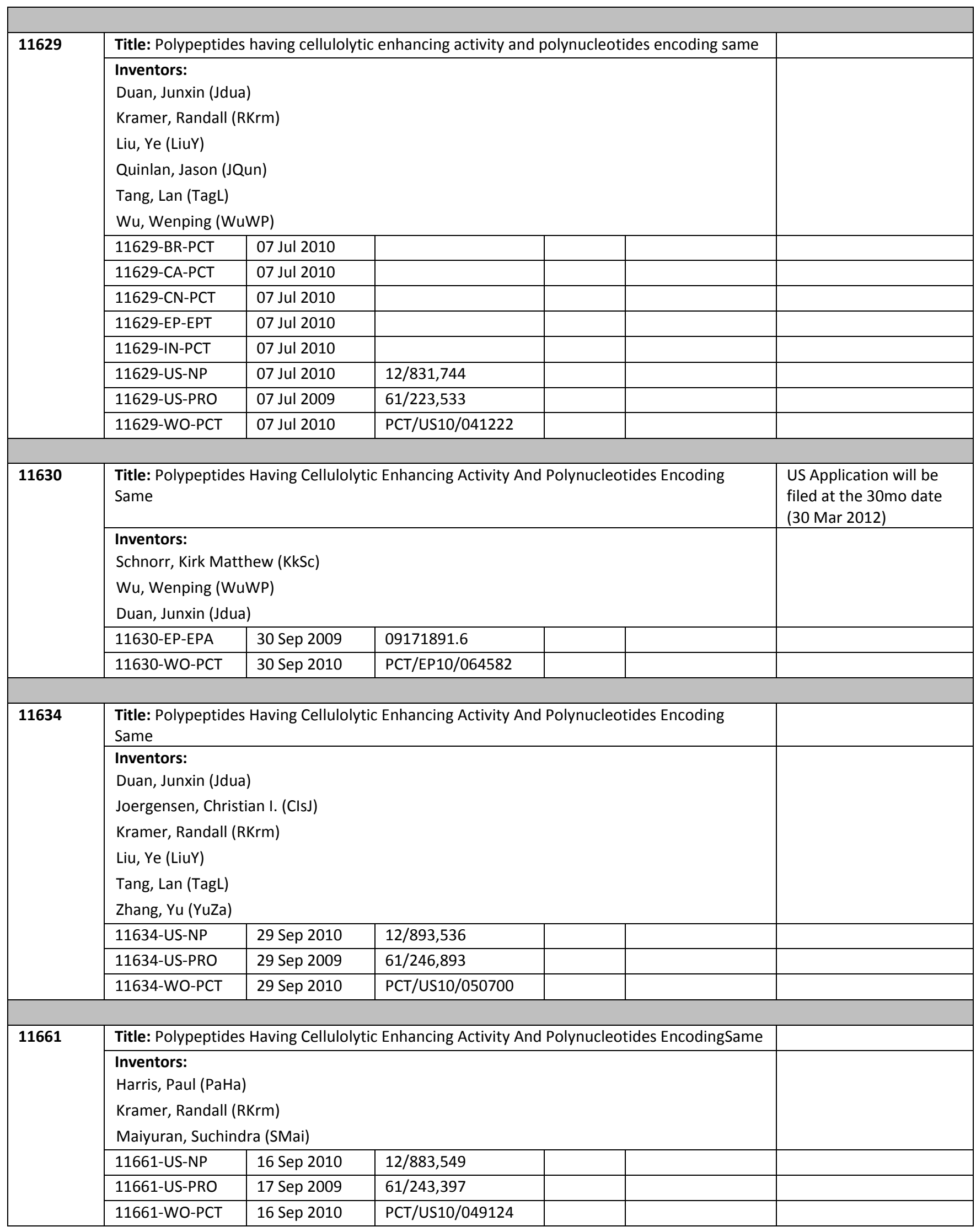


DECREASE Final Technical Report, Novozymes Inc. DE-FC36-08G018080

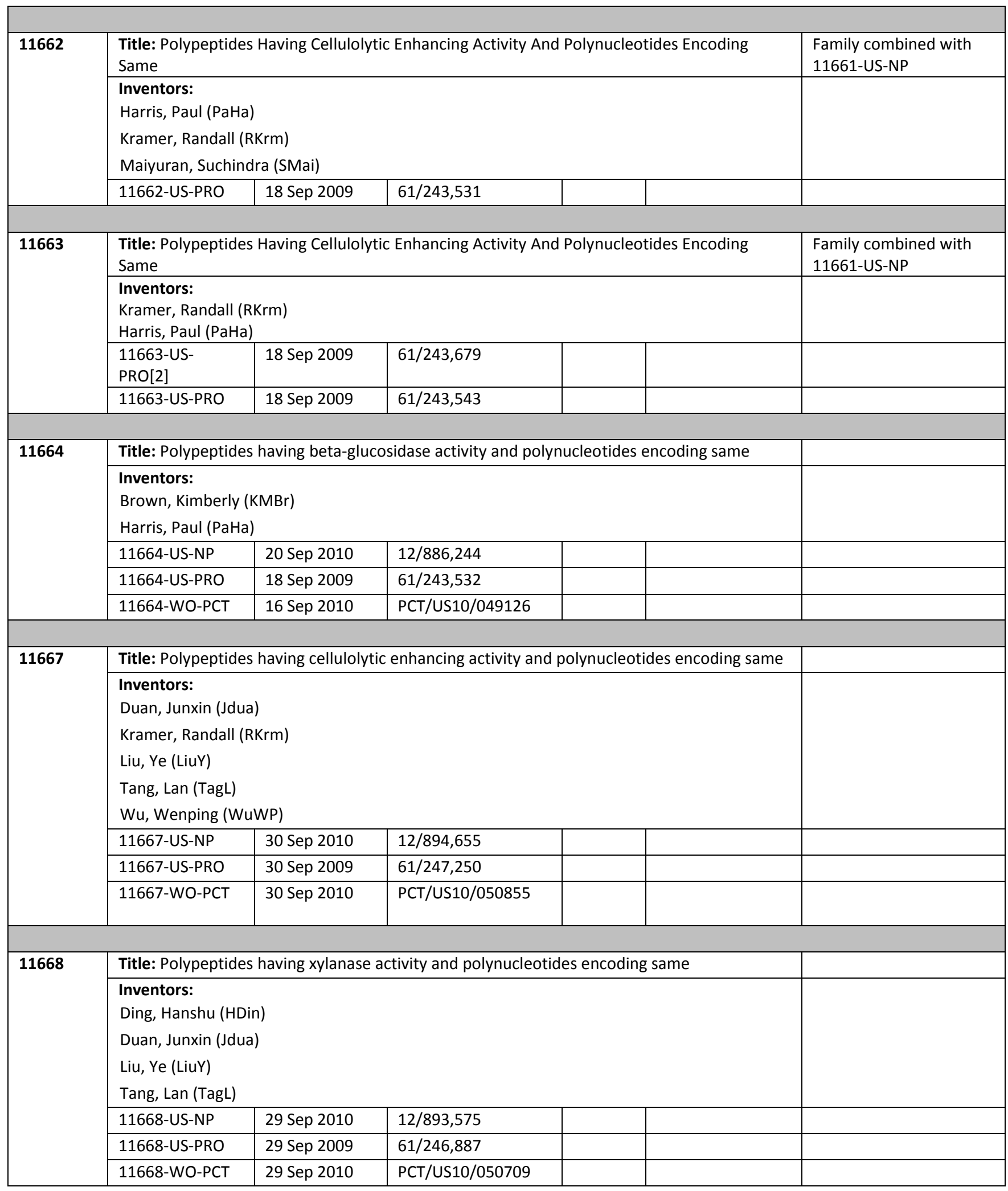




\begin{tabular}{|c|c|c|c|c|c|}
\hline \multirow[t]{5}{*}{11672} & \multicolumn{4}{|c|}{ Title: Cellobiohydrolase variants and polynucleotides encoding same } & \\
\hline & \multicolumn{4}{|l|}{$\begin{array}{l}\text { Inventors: } \\
\text { Wogulis, Mark }\end{array}$} & \\
\hline & 11672-US-NP & 20 Oct 2010 & $12 / 908,339$ & & \\
\hline & 11672-US-PRO & 23 Oct 2009 & $61 / 254,408$ & & \\
\hline & 11672-WO-PCT & 20 Oct 2010 & PCT/US10/053338 & & \\
\hline \multirow[t]{5}{*}{11690} & \multicolumn{4}{|c|}{ Title: Polypeptides having cellobiohydrolase activity and polynucleotides encoding same } & $\begin{array}{l}\text { US Application will be } \\
\text { filed at the } 30 \text { mo date } \\
\text { (06 May 2012) }\end{array}$ \\
\hline & \multicolumn{4}{|c|}{$\begin{array}{l}\text { Inventors: } \\
\text { McBrayer, Brett (BMBy) } \\
\text { Schnorr, Kirk Matthew (KkSc) } \\
\text { Stringer, Mary Ann (MStr) } \\
\text { Vlasenko, Elena (EIVI) }\end{array}$} & \\
\hline & 11690-US-PRO & 06 Nov 2009 & $61 / 258,999$ & & \\
\hline & $\begin{array}{l}\text { 11690-US- } \\
\text { PRO[2] }\end{array}$ & 04 Mar 2010 & $61 / 310,430$ & & \\
\hline & 11690-WO-PCT & 05 Nov 2010 & PCT/US10/55643 & & \\
\hline \multirow[t]{5}{*}{11729} & \multicolumn{4}{|c|}{ Title: Polypeptides having Beta-glucosidase activity and polynucleotides encoding same } & \\
\hline & \multicolumn{4}{|c|}{$\begin{array}{l}\text { Inventors: } \\
\text { Ding, Hanshu (HDin) } \\
\text { Morant, Marc Dominique (MDqM) } \\
\text { Patkar, Shamkant (EX-S. Patkar) }\end{array}$} & \\
\hline & 11729-US-NP & 30 Jun 2011 & $13 / 174,391$ & & \\
\hline & 11729-US-PRO & 30 Jun 2010 & $61 / 360,351$ & & \\
\hline & 11729-WO-PCT & 30 Jun 2011 & PCT/US11/042682 & & \\
\hline \multirow[t]{4}{*}{11730} & \multicolumn{4}{|c|}{ Title: Cellobiohydrolase variants and polynucleotides encoding same } & $\begin{array}{l}\text { US Application will be } \\
\text { filed at the } 30 \text { mo date } \\
\text { (30 Sep 2012) }\end{array}$ \\
\hline & \multicolumn{4}{|c|}{$\begin{array}{l}\text { Inventors: } \\
\text { Wogulis, Mark (MaWo) }\end{array}$} & \\
\hline & 11730-US-PRO & 31 Mar 2010 & $61 / 319,672$ & & \\
\hline & 11730-WO-PCT & 29 Mar 2011 & PCT/US11/030352 & & \\
\hline \multirow[t]{4}{*}{12022} & \multicolumn{4}{|c|}{$\begin{array}{l}\text { Title: Compositions comprising a polypeptide having cellulolytic enhancing activity and a } \\
\text { liquor and uses thereof }\end{array}$} & $\begin{array}{l}\text { US Application will be } \\
\text { filed at the } 30 \text { mo date } \\
\text { (12 Feb 2013) }\end{array}$ \\
\hline & \multicolumn{4}{|c|}{$\begin{array}{l}\text { Inventors: } \\
\text { Higgins, Donald (DoHi) } \\
\text { Quinlan, Jason (JQun) } \\
\text { Sweeney, Matt (MSwn) } \\
\text { Xu, Feng (FXu) } \\
\text { Xu, Hui (HuiX) }\end{array}$} & \\
\hline & 12022-US-PRO & 12 Aug 2010 & $61 / 373,210$ & & \\
\hline & 12022-WO-PCT & 05 Aug 2011 & PCT/US11/046795 & & \\
\hline
\end{tabular}




\begin{tabular}{|c|c|c|c|c|}
\hline \multirow[t]{4}{*}{12023} & \multicolumn{3}{|c|}{$\begin{array}{l}\text { Title: Compositions comprising a polypeptide having cellulolytic enhancing activity and a } \\
\text { dioxy compound and uses thereof }\end{array}$} & $\begin{array}{l}\text { US Application will be } \\
\text { filed at the 30mo date } \\
\text { (12 Feb 2013) }\end{array}$ \\
\hline & \multicolumn{3}{|l|}{ Inventors: } & \\
\hline & 12023-US-PRO & 12 Aug 2010 & $61 / 373,124$ & \\
\hline & 12023-WO-PCT & 05 Aug 2011 & PCT/US11/046780 & \\
\hline \multirow[t]{4}{*}{12024} & \multicolumn{3}{|c|}{$\begin{array}{l}\text { Title: Compositions comprising a polypeptide having cellulolytic enhancing activity and a } \\
\text { bicyclic compound and uses thereof }\end{array}$} & $\begin{array}{l}\text { US Application will be } \\
\text { filed at the } 30 \text { mo date } \\
\text { (12 Feb 2013) }\end{array}$ \\
\hline & \multicolumn{3}{|c|}{$\begin{array}{l}\text { Inventors: } \\
\text { Quinlan, Jason (JQun) } \\
\text { Sweeney, Matt (MSwn) } \\
\text { Xu, Feng (FXu) }\end{array}$} & \\
\hline & 12024-US-PRO & 12 Aug 2010 & $61 / 373,128$ & \\
\hline & 12024-WO-PCT & 05 Aug 2011 & PCT/US11/046754 & \\
\hline \multirow[t]{4}{*}{12025} & \multicolumn{3}{|c|}{$\begin{array}{l}\text { Title: Compositions comprising a polypeptide having cellulolytic enhancing activity and a } \\
\text { heterocyclic compound and uses thereof }\end{array}$} & $\begin{array}{l}\text { US Application will be } \\
\text { filed at the } 30 \text { mo date } \\
\text { (12 Feb 2013) }\end{array}$ \\
\hline & \multicolumn{3}{|c|}{$\begin{array}{l}\text { Inventors: } \\
\text { Quinlan, Jason (JQun) } \\
\text { Sweeney, Matt (MSwn) } \\
\text { Xu, Feng (FXu) }\end{array}$} & \\
\hline & 12025-US-PRO & 12 Aug 2010 & $61 / 373,145$ & \\
\hline & 12025-WO-PCT & 05 Aug 2011 & PCT/US11/046747 & \\
\hline \multirow[t]{4}{*}{12026} & \multicolumn{3}{|c|}{$\begin{array}{l}\text { Title: Compositions comprising a polypeptide having cellulolytic enhancing activity and a } \\
\text { nitrogen-containing compound and uses thereof }\end{array}$} & $\begin{array}{l}\text { US Application will be } \\
\text { filed at the 30mo date } \\
\text { (12 Feb 2013) }\end{array}$ \\
\hline & \multicolumn{3}{|c|}{$\begin{array}{l}\text { Inventors: } \\
\text { Quinlan, Jason (JQun) } \\
\text { Sweeney, Matt (MSwn) } \\
\text { Xu, Feng (FXu) }\end{array}$} & \\
\hline & 12026-US-PRO & 12 Aug 2010 & $61 / 373,150$ & \\
\hline & 12026-WO-PCT & 05 Aug 2011 & PCT/US11/046743 & \\
\hline \multirow[t]{4}{*}{12027} & \multicolumn{3}{|c|}{$\begin{array}{l}\text { Title: Compositions comprising a polypeptide having cellulolytic enhancing activity and a } \\
\text { quinone compound and uses thereof }\end{array}$} & $\begin{array}{l}\text { US Application will be } \\
\text { filed at the } 30 \text { mo date } \\
\text { (12 Feb 2013) }\end{array}$ \\
\hline & \multicolumn{3}{|c|}{$\begin{array}{l}\text { Inventors: } \\
\text { Quinlan, Jason (JQun) } \\
\text { Sweeney, Matt (MSwn) } \\
\text { Xu, Feng (FXu) }\end{array}$} & \\
\hline & 12027-US-PRO & 12 Aug 2010 & $61 / 373,157$ & \\
\hline & 12027-WO-PCT & 05 Aug 2011 & PCT/US11/046720 & \\
\hline
\end{tabular}




\begin{tabular}{|c|c|c|c|c|}
\hline \multirow[t]{4}{*}{12028} & \multicolumn{3}{|c|}{$\begin{array}{l}\text { Title: Compositions comprising a polypeptide having cellulolytic enhancing activity and a } \\
\text { sulfur-containing compound and uses thereof }\end{array}$} & $\begin{array}{l}\text { US Application will be } \\
\text { filed at the } 30 \text { mo date } \\
\text { (12 Feb 2013) }\end{array}$ \\
\hline & \multicolumn{3}{|l|}{$\begin{array}{l}\text { Inventors: } \\
\text { Xu, Feng (FXu) }\end{array}$} & \\
\hline & 12028-US-PRO & 12 Aug 2010 & $61 / 373,166$ & \\
\hline & 12028-WO-PCT & 05 Aug 2011 & PCT/US11/046723 & \\
\hline \multirow[t]{4}{*}{12029} & \multicolumn{3}{|c|}{$\begin{array}{l}\text { Title: Compositions comprising a polypeptide having cellulolytic enhancing activity and an } \\
\text { organic compound and uses thereof }\end{array}$} & $\begin{array}{l}\text { US Application will be } \\
\text { filed at the } 30 \text { mo date } \\
\text { (12 Feb 2013) }\end{array}$ \\
\hline & \multicolumn{3}{|c|}{$\begin{array}{l}\text { Inventors: } \\
\text { Johansen, Katja Salomon (KSJo) } \\
\text { Quinlan, Jason (JQun) } \\
\text { Sweeney, Matt (MSwn) } \\
\text { Xu, Feng (FXu) }\end{array}$} & \\
\hline & 12029-US-PRO & 12 Aug 2010 & $61 / 373,170$ & \\
\hline & 12029-WO-PCT & 05 Aug 2011 & PCT/US11/046725 & \\
\hline \multirow[t]{4}{*}{12033} & \multicolumn{3}{|c|}{$\begin{array}{l}\text { Title: Variants of polypeptides having cellulolytic enhancing activity and polynucleotides } \\
\text { encoding same }\end{array}$} & $\begin{array}{l}\text { US Application will be } \\
\text { filed at the } 30 \text { mo date } \\
\text { (30 Mar 2013) }\end{array}$ \\
\hline & \multicolumn{3}{|c|}{$\begin{array}{l}\text { Inventors: } \\
\text { Sweeney, Matt (MSwn) } \\
\text { Wogulis, Mark (MaWo) }\end{array}$} & \\
\hline & 12033-US-PRO & 30 Sep 2010 & $61 / 388,530$ & \\
\hline & 12033-WO-PCT & 29 Sep 2011 & PCT/US11/054034 & \\
\hline \multirow[t]{4}{*}{12034} & \multicolumn{3}{|c|}{$\begin{array}{l}\text { Title: Variants of polypeptides having cellulolytic enhancing activity and polynucleotides } \\
\text { encoding same }\end{array}$} & $\begin{array}{l}\text { US Application will be } \\
\text { filed at the } 30 \text { mo date } \\
\text { (30 Mar 2013) }\end{array}$ \\
\hline & \multicolumn{3}{|c|}{$\begin{array}{l}\text { Inventors: } \\
\text { Sweeney, Matt (MSwn) } \\
\text { Wogulis, Mark (MaWo) }\end{array}$} & \\
\hline & 12034-US-PRO & 30 Sep 2010 & $61 / 388,527$ & \\
\hline & 12034-WO-PCT & 29 Sep 2011 & PCT/US11/054036 & \\
\hline \multirow[t]{4}{*}{12035} & & & & $\begin{array}{l}\text { US Application will be } \\
\text { filed at the } 30 \text { mo date } \\
\text { (02 May 2013) }\end{array}$ \\
\hline & \multicolumn{3}{|c|}{$\begin{array}{l}\text { Inventors: } \\
\text { Quinlan, Jason (JQun) } \\
\text { Xu, Feng (FXu) }\end{array}$} & \\
\hline & 12035-US-PRO & 02 Nov 2010 & $61 / 409,469$ & \\
\hline & 12035-WO-PCT & 02 Nov 2011 & PCT/US11/058995 & \\
\hline
\end{tabular}


DECREASE Final Technical Report, Novozymes Inc. DE-FC36-08G018080

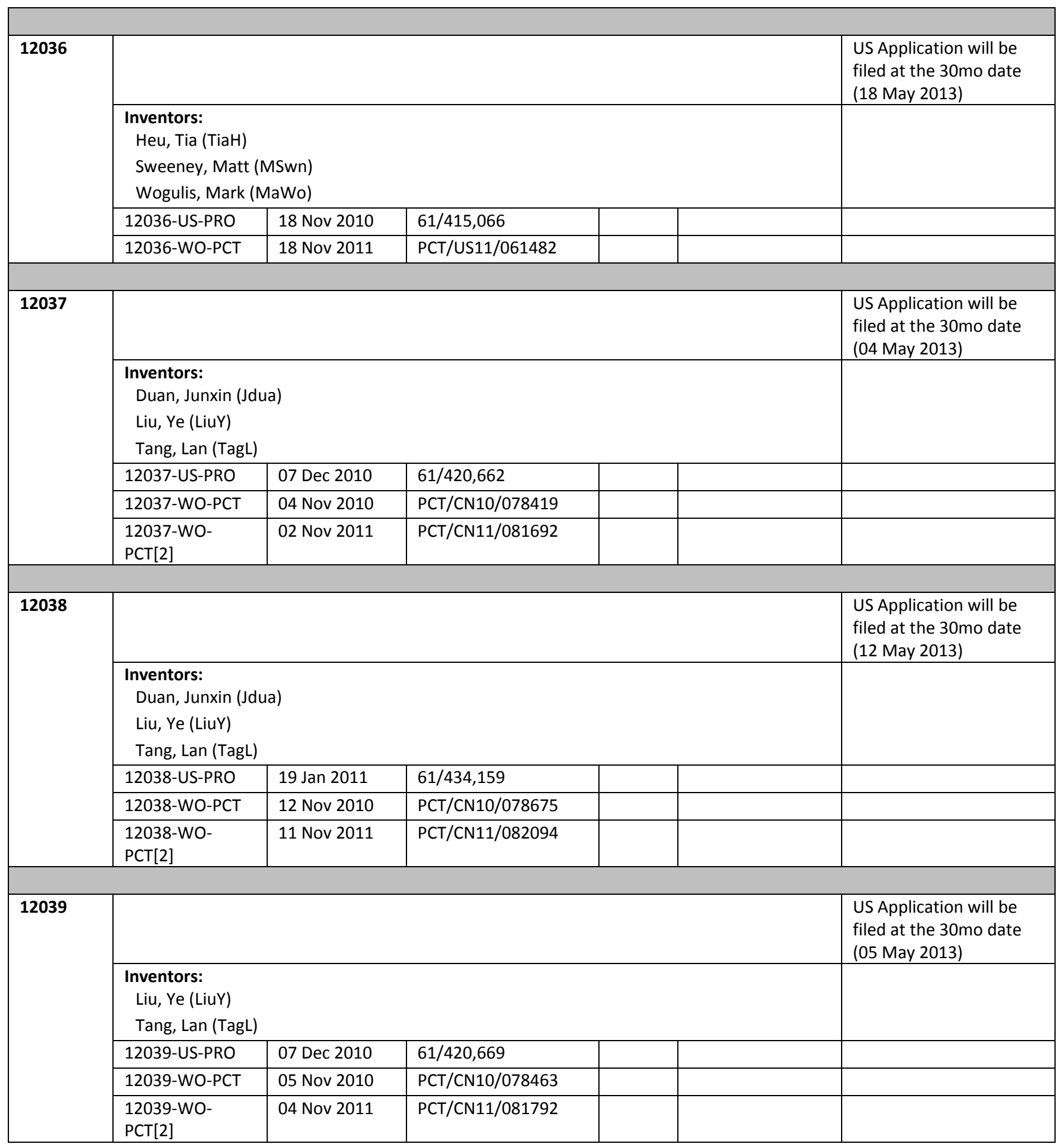


DECREASE Final Technical Report, Novozymes Inc. DE-FC36-08G018080

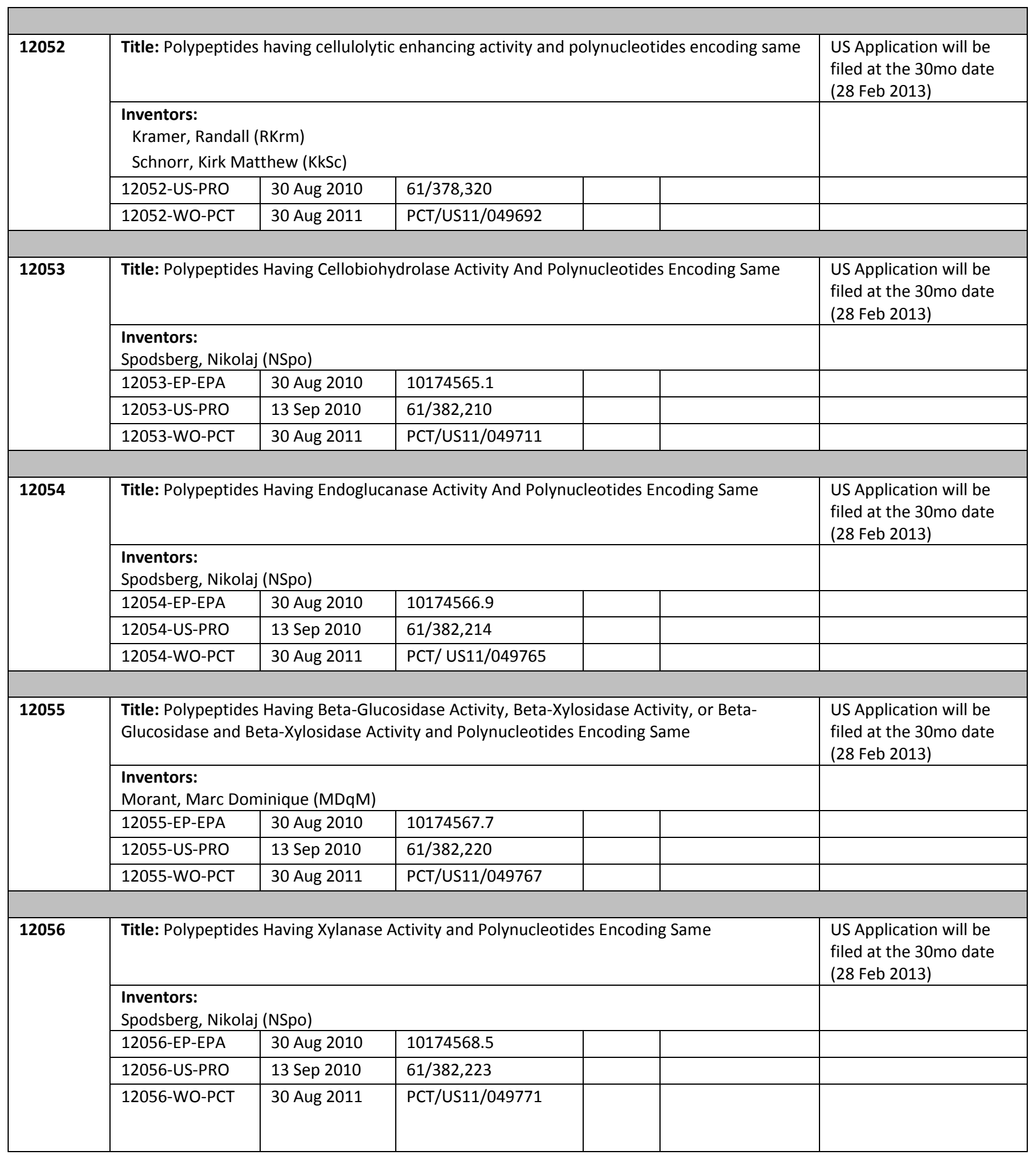


DECREASE Final Technical Report, Novozymes Inc. DE-FC36-08G018080

\begin{tabular}{|c|c|c|c|c|}
\hline \multirow[t]{5}{*}{12057} & \multicolumn{3}{|c|}{ Title: Polypeptides having hemicellulolytic activity and polynucleotides encoding same } & $\begin{array}{l}\text { US Application will be } \\
\text { filed at the } 30 \text { mo date } \\
\text { ( } 28 \text { Feb 2013) }\end{array}$ \\
\hline & \multicolumn{3}{|c|}{$\begin{array}{l}\text { Inventors: } \\
\text { Ding, Hanshu (HDin) } \\
\text { Spodsberg, Nikolaj (NSpo) } \\
\text { Stringer, Mary Ann (MStr) }\end{array}$} & \\
\hline & 12057-EP-EPA & 31 Aug 2010 & 10174570.1 & \\
\hline & 12057-US-PRO & 30 Aug 2010 & $61 / 378,313$ & \\
\hline & 12057-WO-PCT & 30 Aug 2011 & PCT/US11/049785 & \\
\hline \multirow[t]{4}{*}{12060} & \multicolumn{3}{|c|}{ Title: Beta-Glucosidase Variants and Polynucleotides Encoding Same } & $\begin{array}{l}\text { US Application will be } \\
\text { filed at the 30mo date } \\
\text { (01 Apr 2013) }\end{array}$ \\
\hline & \multicolumn{3}{|c|}{$\begin{array}{l}\text { Inventors: } \\
\text { Harris, Paul (PaHa) } \\
\text { Osborn, David (DWOs) } \\
\text { Wogulis, Mark (MaWo) }\end{array}$} & \\
\hline & 12060-US-PRO & 01 Oct 2010 & $61 / 388,997$ & \\
\hline & 12060-US-PCT & 30 Sep 2011 & PCT/US11/054185 & \\
\hline \multirow[t]{3}{*}{12120} & & & & \\
\hline & \multicolumn{3}{|c|}{$\begin{array}{l}\text { Inventors: } \\
\text { McBrayer, Brett (BMBy) } \\
\text { Stringer, Mary Ann (MStr) }\end{array}$} & \\
\hline & 12120-US-PRO & 08 Mar 2011 & $61 / 450,494$ & \\
\hline \multirow[t]{4}{*}{12130} & & & & $\begin{array}{l}\text { US Application will be } \\
\text { filed at the } 30 \text { mo date } \\
\text { (23 Aug 2013) }\end{array}$ \\
\hline & \multicolumn{3}{|c|}{$\begin{array}{l}\text { Inventors: } \\
\text { Duan, Junxin (Jdua) } \\
\text { Tang, Lan (TagL) } \\
\text { Wu, Wenping (WuWP) } \\
\text { Zhang, Yu (YuZa) }\end{array}$} & \\
\hline & 12130-US-PRO & 04 Apr 2011 & $61 / 471,423$ & \\
\hline & 12130-WO-PCT & 23 Feb 2011 & PCT/CN11/071208 & \\
\hline \multirow[t]{3}{*}{12148} & & & & \\
\hline & \multicolumn{3}{|c|}{$\begin{array}{l}\text { Inventors: } \\
\text { Kramer, Randall (RKrm) } \\
\text { Schnorr, Kirk Matthew (KkSc) }\end{array}$} & \\
\hline & 12148-US-PRO & 10 Mar 2011 & $61 / 451,413$ & \\
\hline
\end{tabular}


DECREASE Final Technical Report, Novozymes Inc. DE-FC36-08G018080

\begin{tabular}{|c|c|c|c|c|}
\hline \multirow[t]{4}{*}{12153} & & & & $\begin{array}{l}\text { US Application will be } \\
\text { filed at the } 30 \text { mo date } \\
\text { ( } 25 \text { Oct 2013) }\end{array}$ \\
\hline & \multicolumn{4}{|c|}{$\begin{array}{l}\text { Inventors: } \\
\text { Henriksen, Svend Hostgaard Bang (SVHB) } \\
\text { Tang, Lan (TagL) } \\
\text { Zhang, Yu (YuZa) }\end{array}$} \\
\hline & 12153-US-PRO & 12 May 2011 & $61 / 485,358$ & \\
\hline & 12153-WO-PCT & 25 Apr 2011 & PCT/CN11/073275 & \\
\hline \multirow[t]{4}{*}{12154} & & & & \\
\hline & \multirow{2}{*}{\multicolumn{4}{|c|}{ 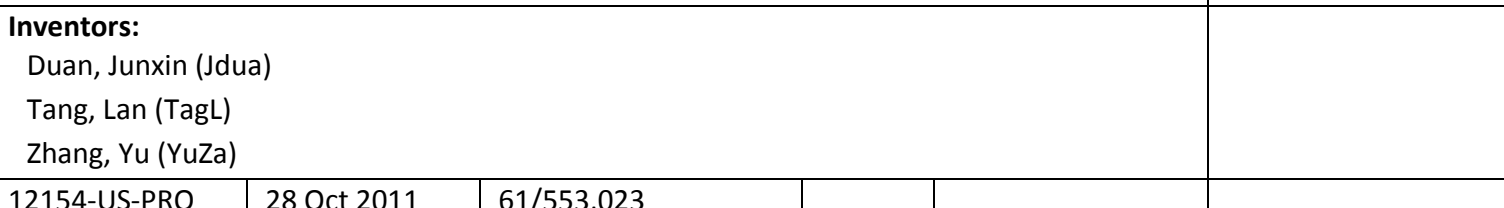 }} \\
\hline & & & & \\
\hline & 12154-WO-PCT & 29 Sep 2011 & PCT/CN11/080367 & \\
\hline \multirow[t]{3}{*}{12167} & & & & \\
\hline & \multicolumn{3}{|c|}{$\begin{array}{l}\text { Inventors: } \\
\text { Cassland, Pierre (PrrC) } \\
\text { McBrayer, Brett (BMBy) } \\
\text { Spodsberg, Nikolaj (NSpo) } \\
\text { Kramer, Randall (RKrm) } \\
\text { Schnorr, Kirk Matthew (KkSc) }\end{array}$} & \\
\hline & 12167-US-PRO & 28 Apr 2011 & $61 / 480,245$ & \\
\hline \multirow[t]{3}{*}{12172} & & & & \\
\hline & \multicolumn{3}{|c|}{$\begin{array}{l}\text { Inventors: } \\
\text { Kramer, Randall (RKrm) } \\
\text { Schnorr, Kirk Matthew (KkSc) }\end{array}$} & \\
\hline & 12172-US-PRO & 31 Mar 2011 & $61 / 470,414$ & \\
\hline \multirow[t]{5}{*}{12186} & & & & \\
\hline & \multicolumn{3}{|c|}{$\begin{array}{l}\text { Inventors: } \\
\text { Harris, Paul (PaHa) } \\
\text { Morant, Marc Dominique (MDqM) }\end{array}$} & \\
\hline & 12186-US-PRO & 06 May 2011 & $61 / 483,116$ & \\
\hline & $\begin{array}{l}\text { 12186-US- } \\
\text { PRO[2] }\end{array}$ & 06 Jul 2011 & $61 / 504,884$ & \\
\hline & $\begin{array}{l}\text { 12186-US- } \\
\text { PRO[3] }\end{array}$ & 13 Oct 2011 & $61 / 546,602$ & \\
\hline
\end{tabular}




\begin{tabular}{|c|c|c|c|c|}
\hline \multirow[t]{3}{*}{12190} & & & & \\
\hline & \multicolumn{3}{|c|}{$\begin{array}{l}\text { Inventors: } \\
\text { McBrayer, Brett (BMBy) } \\
\text { Shaghasi, Tarana (TSHG) }\end{array}$} & \\
\hline & 12190-US-PRO & 29 Apr 2011 & $61 / 480,860$ & \\
\hline \multirow[t]{3}{*}{12193} & & & & \\
\hline & \multicolumn{3}{|c|}{$\begin{array}{l}\text { Inventors: } \\
\text { Tejirian, Ani (ATji) } \\
\text { Widner, William (WWi) } \\
\text { Xu, Feng (FXu) }\end{array}$} & \\
\hline & 12193-US-PRO & 19 May 2011 & $61 / 488,094$ & \\
\hline \multirow[t]{3}{*}{12198} & & & & \\
\hline & \multicolumn{3}{|l|}{$\begin{array}{l}\text { Inventors: } \\
\text { Xu, Feng (FXu) }\end{array}$} & \\
\hline & 12198-US-PRO & 19 May 2011 & $61 / 488,098$ & \\
\hline \multirow[t]{4}{*}{12209} & & & & \\
\hline & \multicolumn{3}{|c|}{$\begin{array}{l}\text { Inventors: } \\
\text { Duan, Junxin (Jdua) } \\
\text { Liu, Ye (LiuY) } \\
\text { Tang, Lan (TagL) } \\
\text { Zhang, Yu (YuZa) }\end{array}$} & \\
\hline & 12209-US-PRO & & & $\begin{array}{l}\text { Will be filed once } \\
\text { secrecy clearance is } \\
\text { done in } \mathrm{CN}\end{array}$ \\
\hline & 12209-WO-PCT & 15 Dec 2011 & PCT/CN11/084093 & \\
\hline \multirow[t]{4}{*}{12210} & & & & \\
\hline & \multicolumn{3}{|c|}{$\begin{array}{l}\text { Inventors: } \\
\text { Duan, Junxin (Jdua) } \\
\text { Liu, Ye (LiuY) } \\
\text { Schnorr, Kirk Matthew (KkSc) } \\
\text { Tang, Lan (TagL) } \\
\text { Zhang, Yu (YuZa) }\end{array}$} & \\
\hline & 12210-US-PRO & 02 Dec 2011 & $61 / 566,035$ & \\
\hline & 12210-WO-PCT & 31 Oct 2011 & PCT/CN11/081569 & \\
\hline \multirow[t]{4}{*}{12211} & & & & \\
\hline & \multicolumn{3}{|c|}{$\begin{array}{l}\text { Inventors: } \\
\text { Duan, Junxin (Jdua) } \\
\text { Liu, Ye (LiuY) } \\
\text { Tang, Lan (TagL) } \\
\text { Zhang, Yu (YuZa) }\end{array}$} & \\
\hline & 12211-US-PRO & 13 Dec 2011 & $61 / 569,910$ & \\
\hline & 12211-WO-PCT & 22 Nov 2011 & PCT/CN11/082627 & \\
\hline
\end{tabular}




\begin{tabular}{|c|c|c|c|c|}
\hline \multirow[t]{4}{*}{12212} & & & & \\
\hline & \multicolumn{4}{|c|}{$\begin{array}{l}\text { Inventors: } \\
\text { Duan, Junxin (Jdua) } \\
\text { Liu, Ye (LiuY) } \\
\text { Tang, Lan (TagL) } \\
\text { Zhang, Yu (YuZa) }\end{array}$} \\
\hline & 12212-US-PRO & & & $\begin{array}{l}\text { Will be filed once } \\
\text { secrecy clearance is } \\
\text { done in } \mathrm{CN}\end{array}$ \\
\hline & 12212-WO-PCT & 19 Dec 2011 & PCT/CN11/084228 & \\
\hline \multirow[t]{4}{*}{12217} & & & & \\
\hline & \multicolumn{4}{|c|}{$\begin{array}{l}\text { Inventors: } \\
\text { Duan, Junxin (Jdua) } \\
\text { Liu, Ye (LiuY) } \\
\text { Tang, Lan (TagL) } \\
\text { Zhang, Yu (YuZa) }\end{array}$} \\
\hline & 12217-US-PRO & 28 Nov 2011 & $61 / 564,090$ & \\
\hline & 12217-WO-PCT & 04 Nov 2011 & РCT/CN11/081802 & \\
\hline \multirow[t]{4}{*}{12218} & & & & \\
\hline & \multicolumn{4}{|c|}{$\begin{array}{l}\text { Inventors: } \\
\text { Duan, Junxin (Jdua) } \\
\text { Liu, Ye (LiuY) } \\
\text { Tang, Lan (TagL) } \\
\text { Zhang, Yu (YuZa) }\end{array}$} \\
\hline & 12218-US-PRO & 02 Dec 2011 & $61 / 566,170$ & \\
\hline & 12218-WO-PCT & 15 Nov 2011 & PCT/CN11/082238 & \\
\hline \multirow[t]{4}{*}{12219} & & & & \\
\hline & \multicolumn{4}{|c|}{$\begin{array}{l}\text { Inventors: } \\
\text { Duan, Junxin (Jdua) } \\
\text { Liu, Ye (LiuY) } \\
\text { Tang, Lan (TagL) } \\
\text { Zhang, Yu (YuZa) }\end{array}$} \\
\hline & 12219-US-PRO & & & $\begin{array}{l}\text { Will be filed once } \\
\text { secrecy clearance is } \\
\text { done in } \mathrm{CN}\end{array}$ \\
\hline & 12219-WO-PCT & 16 Dec 2011 & PCT/US11/084139 & \\
\hline \multirow[t]{4}{*}{12221} & & & & \\
\hline & \multicolumn{4}{|c|}{$\begin{array}{l}\text { Inventors: } \\
\text { Duan, Junxin (Jdua) } \\
\text { Liu, Ye (LiuY) } \\
\text { Tang, Lan (TagL) } \\
\text { Zhang, Yu (YuZa) }\end{array}$} \\
\hline & 12221-US-PRO & & & $\begin{array}{l}\text { Will be filed once } \\
\text { secrecy clearance is } \\
\text { done in } \mathrm{CN}\end{array}$ \\
\hline & 12221-WO-PCT & 18 Nov 2011 & PCT/CN11/082460 & \\
\hline
\end{tabular}


DECREASE Final Technical Report, Novozymes Inc. DE-FC36-08G018080

\begin{tabular}{|c|c|c|c|c|}
\hline \multirow[t]{4}{*}{12222} & & & & \\
\hline & \multicolumn{4}{|c|}{$\begin{array}{l}\text { Inventors: } \\
\text { Duan, Junxin (Jdua) } \\
\text { Liu, Ye (LiuY) } \\
\text { Tang, Lan (TagL) } \\
\text { Zhang, Yu (YuZa) }\end{array}$} \\
\hline & 12222-US-PRO & 01 Dec 2011 & $61 / 565,782$ & \\
\hline & 12222-WO-PCT & 28 Oct 2011 & PCT/CN11/081495 & \\
\hline \multirow[t]{4}{*}{12223} & & & & \\
\hline & \multicolumn{4}{|c|}{$\begin{array}{l}\text { Inventors: } \\
\text { Duan, Junxin (Jdua) } \\
\text { Liu, Ye (LiuY) } \\
\text { Tang, Lan (TagL) } \\
\text { Zhang, Yu (YuZa) }\end{array}$} \\
\hline & 12223-US-PRO & & & $\begin{array}{l}\text { Will be filed once } \\
\text { secrecy clearance is } \\
\text { done in } \mathrm{CN}\end{array}$ \\
\hline & 12223-WO-PCT & 22 Nov 2011 & PCT/CN11/082629 & \\
\hline \multirow[t]{4}{*}{12224} & & & & \\
\hline & \multicolumn{4}{|c|}{$\begin{array}{l}\text { Inventors: } \\
\text { Duan, Junxin (Jdua) } \\
\text { Liu, Ye (LiuY) } \\
\text { Tang, Lan (TagL) } \\
\text { Zhang, Yu (YuZa) }\end{array}$} \\
\hline & 12224-US-PRO & 02 Dec 2011 & $61 / 566,167$ & \\
\hline & 12224-WO-PCT & 11 Nov 2011 & PCT/CN11/082091 & \\
\hline \multicolumn{5}{|l|}{12225} \\
\hline & \multicolumn{4}{|c|}{$\begin{array}{l}\text { Inventors: } \\
\text { Duan, Junxin (Jdua) } \\
\text { Liu, Ye (LiuY) } \\
\text { Tang, Lan (TagL) } \\
\text { Zhang, Yu (YuZa) } \\
\end{array}$} \\
\hline & 12225-US-PRO & & & $\begin{array}{l}\text { Will be filed once } \\
\text { secrecy clearance is } \\
\text { done in } \mathrm{CN}\end{array}$ \\
\hline & 12225-WO-PCT & 01 Dec 2011 & PCT/CN11/083276 & \\
\hline \multirow[t]{4}{*}{12226} & & & & \\
\hline & \multicolumn{4}{|c|}{$\begin{array}{l}\text { Inventors: } \\
\text { Duan, Junxin (Jdua) } \\
\text { Liu, Ye (LiuY) } \\
\text { Tang, Lan (TagL) } \\
\text { Zhang, Yu (YuZa) }\end{array}$} \\
\hline & 12226-US-PRO & & & $\begin{array}{l}\text { Will be filed once } \\
\text { secrecy clearance is } \\
\text { done in } \mathrm{CN}\end{array}$ \\
\hline & 12226-WO-PCT & 19 Dec 2011 & PCT/CN11/084230 & \\
\hline
\end{tabular}




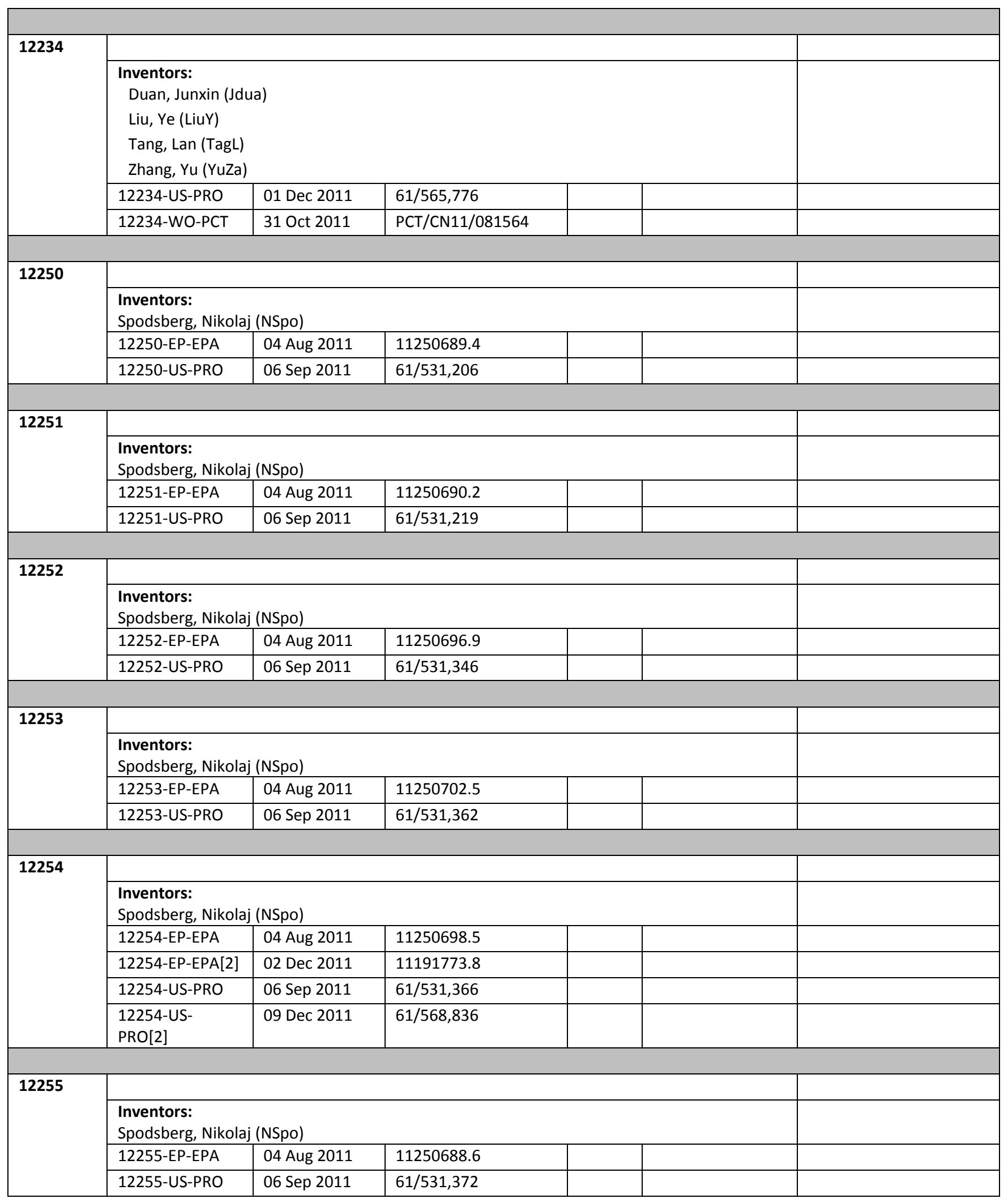




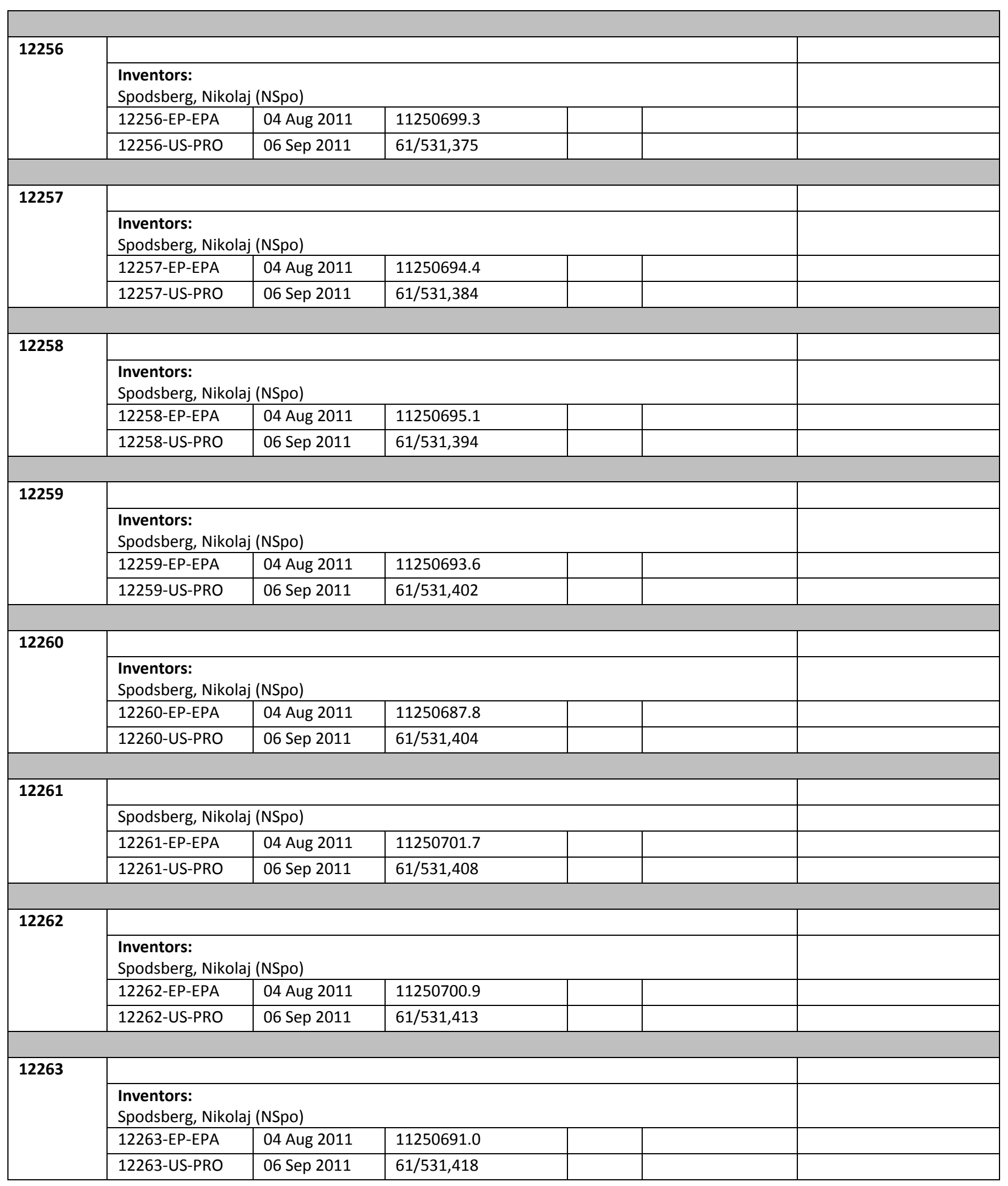




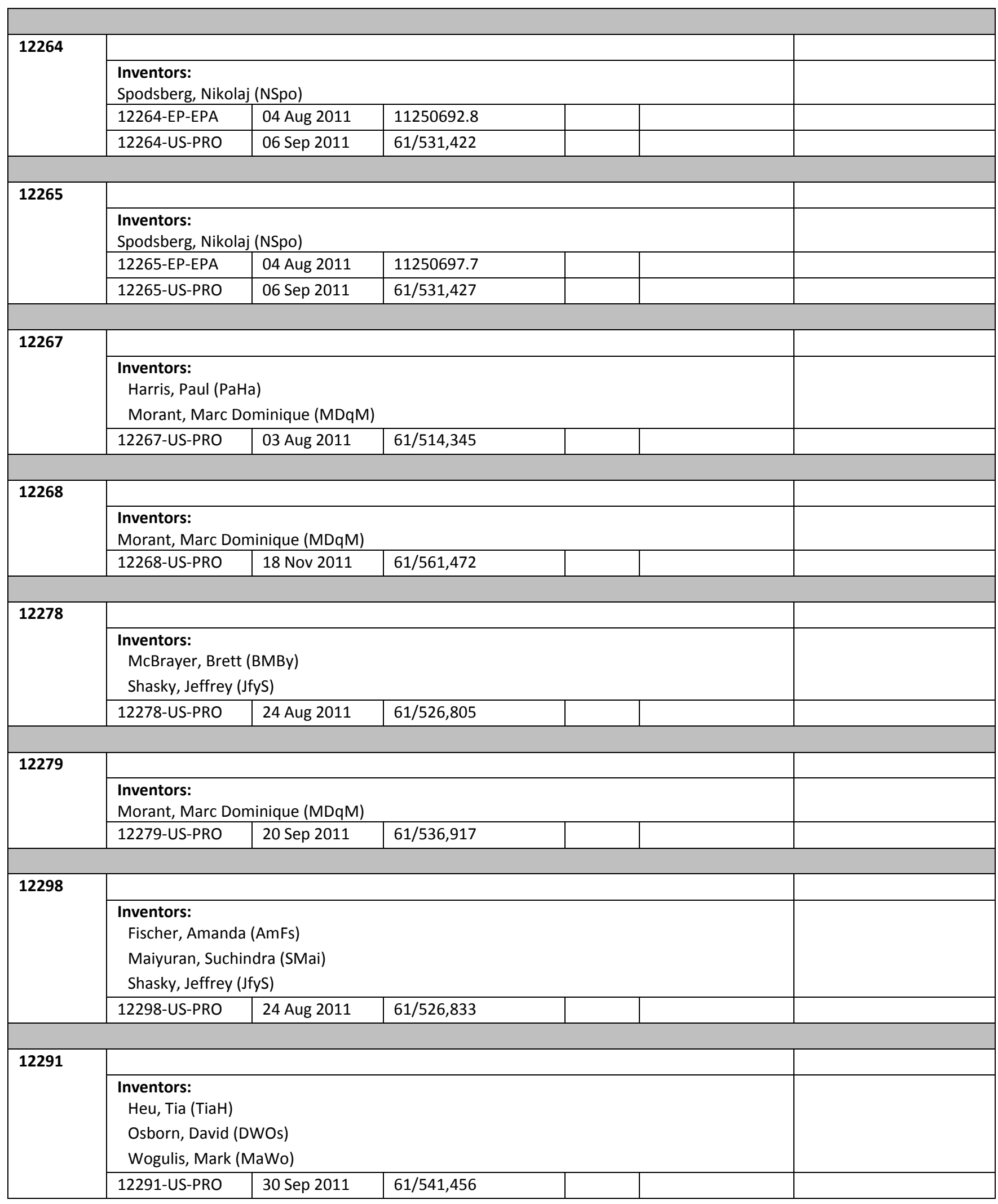




\begin{tabular}{|c|c|c|c|}
\hline \multirow[t]{3}{*}{12318} & & & \\
\hline & \multicolumn{3}{|c|}{$\begin{array}{l}\text { Inventors: } \\
\text { Liu, Ye (LiuY) } \\
\text { Shaghasi, Tarana (TSHG) }\end{array}$} \\
\hline & 12318-WO-PCT & 22 Dec 2011 & PCT/CN2011/084419 \\
\hline \multirow[t]{3}{*}{12325} & & & \\
\hline & \multicolumn{3}{|c|}{$\begin{array}{l}\text { Inventors: } \\
\text { Morant, Marc Dominique (MDqM) }\end{array}$} \\
\hline & 12325-US-PRO & 18 Nov 2011 & $61 / 561,470$ \\
\hline \multirow[t]{3}{*}{12326} & & & \\
\hline & \multicolumn{3}{|c|}{$\begin{array}{l}\text { Inventors: } \\
\text { Morant, Marc Dominique (MDqM) }\end{array}$} \\
\hline & 12326-US-PRO & 18 Nov 2011 & $61 / 561,448$ \\
\hline \multirow[t]{3}{*}{12327} & & & \\
\hline & \multicolumn{3}{|c|}{$\begin{array}{l}\text { Inventors: } \\
\text { Morant, Marc Dominique (MDqM) }\end{array}$} \\
\hline & 12327-US-PRO & 18 Nov 2011 & $61 / 561,446$ \\
\hline \multirow[t]{3}{*}{12342} & & & \\
\hline & \multicolumn{3}{|c|}{$\begin{array}{l}\text { Inventors: } \\
\text { Beresford, Leslie (LsBf) } \\
\text { Bohan, Doreen (DFng) } \\
\text { Lamsa, Michael (MHLa) } \\
\text { Lin, Janine (JLin) } \\
\text { Maranta, Michelle (MMar) }\end{array}$} \\
\hline & 12342-US-PRO & 21 Nov 2011 & $61 / 562,277$ \\
\hline \multirow[t]{3}{*}{12358} & & & \\
\hline & \multicolumn{3}{|c|}{$\begin{array}{l}\text { Inventors: } \\
\text { Wogulis, Mark (MaWo) }\end{array}$} \\
\hline & 12358-US-PRO & 20 Dec 2011 & $61 / 578,062$ \\
\hline \multirow[t]{3}{*}{12361} & & & \\
\hline & \multicolumn{3}{|c|}{$\begin{array}{l}\text { Inventors: } \\
\text { Spodsberg, Nikolaj (NSpo) } \\
\text { Shaghasi, Tarana (TSHG) }\end{array}$} \\
\hline & 12361-US-PRO & 16 Dec 2011 & $61 / 576,518$ \\
\hline \multirow[t]{3}{*}{12364} & & & \\
\hline & \multicolumn{3}{|c|}{$\begin{array}{l}\text { Inventors: } \\
\text { Spodsberg, Nikolaj (NSpo) } \\
\text { Shaghasi, Tarana (TSHG) }\end{array}$} \\
\hline & 12364-US-PRO & 19 Dec 2011 & $61 / 577,644$ \\
\hline
\end{tabular}




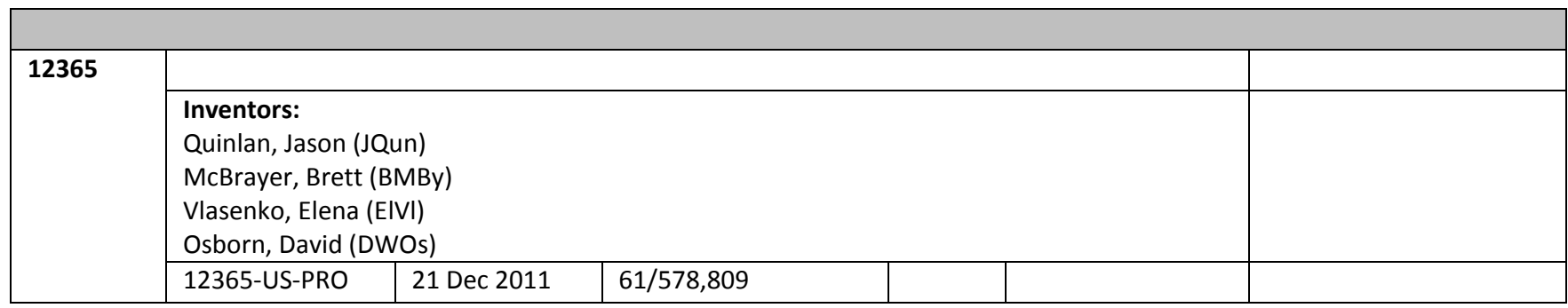

\section{References}

1. Aden, A., et al., Lignocellulosic Biomass to Ethanol Process Design and Economics Utilizing Co-current Dilute Acid Prehydrolysis and Enzymatic Hydrolysis for Corn Stover, in Technical Report, L. Montague, A. Slayton, and J. Lukas, Editors. 2002, National Renewable Energy Laboratory: 1617 Cole Boulevard Golden, CO 80401.

2. Dotson, W.D., J. Greenier, and H. Ding, Polypeptides Having Cellulolytic Enhancing Activity and Polynucleiotides Encoding Same, in WO 2005/074656. 2005, Novozymes, Inc.

3. Harris, P.V., et al., Stimulation of lignocellulosic biomass hydrolysis by proteins of glycoside hydrolase family 61: structure and function of a large, enigmatic family. Biochemistry, 2010. 49(15): p. 3305-16.

4. Quinlan, R.J., et al., Insights into the oxidative degradation of cellulose by a copper metalloenzyme that exploits biomass components. Proc Natl Acad Sci U S A, 2011. 108(37): p. 15079-84.

5. Langston, J.A., et al., Oxidoreductive cellulose depolymerization by the enzymes cellobiose dehydrogenase and glycoside hydrolase 61. Appl Environ Microbiol, 2011. 77(19): p. 7007-15. 